H.H. Grotheer, K. Wolf, K. Hoffmann

Photoionization mass spectrometry for the investigation of combustion generated nascent nanoparticles and their relation to laser induced incandescence

Appl. Phys. B 104 (2011), 367-383.

The original publication is available at www.springerlink.com

http://dx.doi.org/10.1007/s00340-011-4403-9 


\title{
Photoionization Mass Spectrometry for the Investigation of Combustion Generated Nascent Nanoparticles and their Relation to Laser Induced Incandescence
}

\author{
Horst-Henning Grotheer ${ }^{1}$, Katrin Wolf and Kai Hoffmann \\ DLR Institute of Combustion Technology, Pfaffenwaldring 38, 70569 Stuttgart, Germany
}

\begin{abstract}
Premixed laminar flat ethylene flames were investigated for nascent nanoparticles through photo ionization mass spectrometry (PIMS). Using an atmospheric McKenna burner and ethylene air flames coupled to an atmospheric sampling system, within a relatively narrow $\mathrm{C} / \mathrm{O}$ range two modes of these particles were found which can be clearly distinguished with regard to their temperature dependence, their reactivity, and their ionization behaviour. Behind a diesel engine the same particles were observed.

These results were corroborated using a low pressure ethylene- $\mathrm{O}_{2}$ flame coupled to a high resolution mass spectrometer. In this case, due to a special inlet system it was possible to operate the flame in a fairly wide $\mathrm{C} / \mathrm{O}$ range without clogging of the inlet nozzles. This allowed to pursue the development of particle size distribution functions (PSDF) well into the regime of mature soot. In addition, on the low mass side of the particle spectra measurements with unity resolution were possible and this allowed to gain information concerning their growth mechanism and structure.

Finally, in an attempt to mimic Laser Induced Incandescence (LII) experiments the soot-laden molecular beam was exposed to IR irradiation. This resulted in a near complete destruction of nascent particles under LII typical fluences. Small C clusters between 3 and $17 \mathrm{C}$ atoms were found. In addition and with much higher intensities clusters comprising several hundreds of $\mathrm{C}$ atoms were also detected, the latter even at very low fluences when small clusters were totally absent.
\end{abstract}

\section{Introduction}

Soot particle sizes are reported to cover the wide size range between $2 \mathrm{~nm}$ and $10 \mu \mathrm{m}^{1}$ corresponding to an atomic mass range between about $1000 \mathrm{u}$ and beyond $10^{10} \mathrm{u}^{2}$. Only small particles consist of singular spheres, so-called primary particles with typical diameters around $10 \mathrm{~nm}^{1}$ and atomic masses around $500 \mathrm{ku}$. Larger particles are composed of chain-like aggregates of these primary particles. Particles between 2 and $10 \mathrm{~nm}$ are often referred to as nascent nanoparticles or soot precursor particles as they fill the gap between molecular precursors such as heavy PAHs and primary particles which are quite often characterized through their crystallinity ${ }^{1}$ i.e. a feature clearly indicating their solid state character. The border between precursor particles and primary particles is still under debate. Instead of the $10 \mathrm{~nm}$ quoted above values around $5 \mathrm{~nm}$ were recently derived from SAXS (small-angle Xray scattering) experiments in flames ${ }^{3}$.

For the measurement of soot in the quoted large size range many methods have been developed. Indeed, as early as 1973 Wersborg et al. ${ }^{4}$ discovered extremely small nanoparticles (diameters down to $2 \mathrm{~nm}$ ) through electron microscopy of particles extracted from low pressure $\mathrm{C}_{2} \mathrm{H}_{2} / \mathrm{O}_{2}$ flames by means of a molecular beam. Later on the same authors modified

\footnotetext{
${ }^{1}$ Corresponding author. Phone +49711 6862378. email: h-h.grotheer@dlr.de
} 
their apparatus to become a kind of mass spectrometer ${ }^{5}$ and found charged particles with even smaller sizes around $1.2 \mathrm{~nm}$. Subsequently, for a large variety of flame conditions nanoparticles were found using very diverse measurement methods such as UV extinction and fluorescence (D'Alessio et al. ${ }^{6,7}$ ), transmission electron microscopy, TEM (Vander Wal ${ }^{8}$, Dobbins ${ }^{9}$ ) and laser microprobe mass spectrometry, LMMS (Dobbins et al. ${ }^{10}$ ). Several new methods for nanoparticle measurement have been worked out more recently by researchers from Naples, including atomic force microscopy, AFM (Barone et al. ${ }^{11}$ ), electrospray differential mobility analysis, EDMA (Sgro et al. ${ }^{12}$ ), and size exclusion chromatography, SEC (Apicella et al. ${ }^{13}$ ). Further progress with regard to differential mobility analysis (DMA) has been achieved through improved sampling techniques ${ }^{14,15}$. This made it possible to reliably measure particle sizes down to $2.4 \mathrm{~nm}$. Using these improved techniques it could be shown behind sooting ethylene flames that under certain conditions particle size distribution functions (PSDF) are bimodal, with the two modes being separated by a "valley" around $6 \mathrm{~nm}$ ${ }^{16}$ and this is very similar to the SAXS derived value quoted above. In this context bimodality means that soot precursor particles are regarded as one mode and soot as the other one. Minutolo et al. ${ }^{17}$ have pushed the lower size limit of DMA even to $2 \mathrm{~nm}$. Photo ionization as a method to cover the entire range from molecules to young soot was introduced by our group ${ }^{18}$ and it showed the existence of soot precursing nanoparticles as a species between PAHs and soot.

It has to be noted, however, that mass spectrometry is distinct from the other methods in an important regard. For mass spectrometry the detection limit at the upper end of the mass or size scale is a restriction for the measurement of soot. For the other methods, by contrast, the detection limit for small sizes may be critical as to be demonstrated using particle measurement through combined extinction and scattering and DMA, respectively, as examples.

D'Alessio and coworkers showed in many papers (see e.g. ${ }^{19}$ ) that the amount of UV light scattered by a particle scales as $\mathrm{D}^{6}$ (D diameter) and its UV extinction scales as $\mathrm{D}^{3}$. Measurement of these two observables allows therefore the deduction of $\mathrm{D}$, provided the scattering can be measured with sufficient accuracy but this may be difficult for low D.

The other example is DMA which is well established for particle sizes beyond $10 \mathrm{~nm}$. For the size region 2-4 nm, however, Minutolo and coworkers ${ }^{20}$ could show that a significant drop of the instrument efficiency occurs which is caused by a severe drop of the CPC (condensation particle counter) sensitivity along with a size-dependent loss caused by diffusion. Furthermore, the ionization efficiency of the charger is also size-dependent so that a total correction factor of up to several orders of magnitude has to applied to the measured particle concentrations. This clearly sets a lower limit to DMA instruments.

The situation is entirely different for mass spectrometers with a molecular beam inlet (MBMS). These instruments are used for gas phase analysis so that normally a mass range between 1 and several $100 \mathrm{u}$ is sufficient. The extension of the mass range is easily possible by using time-of-flight instruments (TOF) as these spectrometers offer in principle an infinite mass range ${ }^{21}$. Through coupling photo ionization sources to TOF instruments effective ionization schemes for heavy PAHs and light particles up to some $10 \mathrm{ku}^{22}$ were developed. By applying suitable means to overcome the inertia of heavy ions along with post-acceleration before detection, it is now possible to measure up to $1 \mathrm{Mu}^{18}$. Obviously, for mass spectrometers the limitation is on the high mass side. This limit allows the measurement of primary particles, but not of mature soot. The region of nascent nanoparticles is completely covered. Very small nanoparticles can even be measured with unity resolution $(R=M / \Delta M \sim$ 5000) for state of the art commercial instruments). This is important as it yields hints on structures $^{23}$. The most relevant feature, however, is that gas phase spectra are furnished simultaneously (at least in principle) to particle distribution spectra so that formation 
mechanisms can be derived. This feature is unique to mass spectrometry and is unmatched by any other particle measurement technique.

There are, however, also serious drawbacks involved in flame mass spectrometry. Unlike nonintrusive optical methods it requires a sampling device. Even when the latter is carefully designed a disturbance of the flame can rarely be excluded. The other disadvantage is that sensitivities may be species dependent as well as mass dependent so that measurements in a wide mass range including many different species may be compromised. Some of these effects are to be discussed in the subsequent section.

For completeness, two other types of mass spectrometers suitable for particle measurement are reported. One of them is the PMS (Particle Mass Spectrometer) pioneered by Roth and coworkers ${ }^{24}$ and refined at KIT, Karlsruhe ${ }^{25}$. This instrument uses "natural" flame ions. Their abundances and hence the sensitivity of the instrument are strongly dependent on the respective ionization potentials and on the temperature. In addition, mass separation is achieved exploiting the deflection of molecular beam ions through an electric field. This allows only a very moderate resolution so that measurements of gas phase molecules are impossible. The other instrument is the Aerosol Time-of-Flight Mass Spectrometer (ATOFMS) as developed by several groups, among them Prather and coworkers ${ }^{26}$. These instruments make use of the so-called slip in a molecular beam, i.e. a mass dependent deviation between particle velocity and mean beam velocity. Particles can thus be characterized through their time of flight although this separation principle works only for heavy particles $(>0.1 \mu \mathrm{m})$.

Generally it can be stated that mass spectrometry combining gas phase and early particle phase detection is a valuable tool for monitoring nascent nanoparticles and their formation mechanisms.

The aim of this paper is to describe in the "Experimental" section the mass spectrometers used in this study along with a description of their drawbacks. The "Result" section reports data obtained in different experimental environments such as high and low pressure flames and an engine. In "Discussion" it is attempted to derive a more general picture from these data.

\section{Experimental}

Two types of set-ups are to be described in this section, i.e. (i) an apparatus called Mobile system which is suitable for samples under normal pressure such as atmospheric flames and engine exhaust gas. (ii) The other apparatus called Stationary system uses a continuous molecular beam and is only suitable for samples under low pressure. Drawbacks that are common to both systems are to be addressed first.

\section{a) Obstacles to obtain quantitative distribution functions over a broad mass range}

Corner-turning effect ${ }^{27}$ : It occurs in molecular beam mass spectrometers (MBMS) when the axes of the beam and of the analyzer, respectively, are orthogonal to each other. This is the common geometry and it offers the advantage that the velocity components of the neutrals in the direction of the MS axis are small and hence only a small effect on mass resolution results. In addition, it prevents the neutral beam from entering the analyzer so that contamination of the instrument is reduced. The problem is that upon ionization the direction of the ions has to be changed which is the more difficult the heavier the ions are so that heavy ions may be completely lost. There are several possibilities to overcome this problem,

- Ion extraction fields as high as possible,

- Location of the ionizing laser beam above the MS axis so as to allow for a wider parabola for the ion trajectories, 
- Reduction of the particle velocity. This can be achieved though operating the beam forming nozzle under reduced stagnation pressure leading to an enhanced slip, i.e. heavy particles lag significantly behind the velocity of the carrier gas.

Mass discrimination through multiplier gain ${ }^{27}$ : The capability of ions to dislodge secondary electrons at the entrance of the multiplier seems to be a function of their momentum which obviously becomes smaller for heavy ions leading to mass dependent sensitivity profiles and even a cut-off for high masses. Although this does not impair the measured mass of a given ion, it does, however, distort particle size distribution functions. The problem is tackled by using a post-acceleration stage in front of the multiplier. It was demonstrated in the literature ${ }^{27}$ that with a post-acceleration of only $14 \mathrm{kV}$ fairly constant sensitivity curves over a mass range up to $500 \mathrm{ku}$ could be achieved.

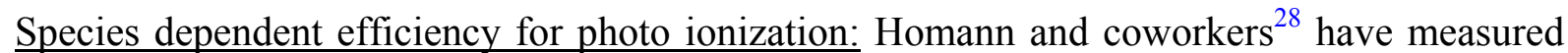
photo ionization efficiencies for a series of PAHs and oxygen-containing PAHs. For a fixed wavelength $(208 \mathrm{~nm})$ they found that ionization effiencies deviate by as much as a factor of 5 in either direction when PAHs are considered. This spread in efficiencies is even larger when comparing oxygen-containing PAHs. For the measurement of particle size distribution functions (PSDF) of soot and its precursors, the problem of species dependent sensitivity translates into a problem of mass dependent sensitivity since as a function of mass two modifications of nascent particles are found which differ with regard to their ionization features (see below) so that different ionization efficiencies are to be anticipated. In the absence of suitable calibrants, there is no immediate solution of this problem available.

\section{b) Mobile system}

This apparatus is used mainly for atmospheric flame measurements and for engine exhaust gases. It has been recently described in some detail ${ }^{29}$. Its main features are as follows. A pending arrangement of the flight tube (analyzer) involving a vertical ion flight path is used to allow for a smaller size of the instrument. The molecular beam which is delivered via a pulsed valve is parallel to the analyzer axis. This so-called axial geometry avoids the corner turning effect, yet this is on the expense of mass spectrometric resolution which is only about $M / \Delta M$ $\sim 1000$. The post-acceleration is only moderate, i.e. $8 \mathrm{kV}$ and this allows ions of about $100 \mathrm{ku}$ to be measured reliably. The mass spectrometer (Reflectron MS) was built by S. Käsdorf, Munich.

A fast flow sampling system is used to suppress undesired reactions in the sampling line. Sample gas is sucked through a nozzle $(0.6 \mathrm{~mm}$ diameter, choked flow) into a quartz or stainless steel tube $(6 \mathrm{~mm}$ id). A He flow is mixed to the sample gas flow right downstream of the sampling nozzle. It is important that a fast sample gas flow is maintained permanently via the sampling nozzle and the pulsed valve. The length of the sampling line was kept as short as possible, typically $50 \mathrm{~cm}$. Pressures in the sampling tube are between 30 and 80 mbar. This pressure drop relative to the flame pressure together with short residence times (of only several $\mathrm{ms}$ ) lead to a reduced influence of fast subsequent reactions. This comes at the expense of sensitivity as most of the sample is lost into the forepump. Another drawback of this sampling method is that it needs relatively large sample gas flows of up to $2.0 \mathrm{slm}$ (standard liters per minute). Furthermore, as with any intrusive method, a disturbance through the probe cannot be excluded when measuring small laboratory flames. Clogging of the nozzle by soot was not a problem since we used only moderately rich flames and because of the short measurement times of about $90 \mathrm{~s}$ for a single run. 


\section{c) Stationary system}

This cross-beam system has also been described recently ${ }^{23,30}$. It is used for the investigation of low pressure (typically 200 mbar) flames. Flame gases are sucked via a conical quartz nozzle $(1 \mathrm{~mm})$ and diluted by carrier gas He. This mixture flows through a short flow reactor (15 cm long, $2 \mathrm{~cm}$ wide) pumped to about 2 mbar and serving as a duct to the second nozzle (1-2 mm). Here, the molecular sample beam is formed and subsequently skimmed.

In molecular beam mass spectrometry (MBMS) mostly only one nozzle combined with a skimmer is used (see e.g. Refs. 31, 32). In this case the nozzle protrudes into the flame. Depending on the flame pressure, this limits the nozzle diameter and clogging by soot may become a problem. Our two-nozzle arrangement offers the advantage that the first nozzle can be relatively wide. By using a large reactor pump $\left(200 \mathrm{~m}^{3} / \mathrm{h}\right)$ the reactor pressure can be kept low allowing for an even larger diameter of the second nozzle. This reduces the subsequent intensity decline in the molecular beam so that a high sensitivity is achieved. In addition, due to the low reactor pressure $(<2 \mathrm{mbar})$ a high amount of slip is made possible in the subsequent beam, and this is one means to reduce the corner-turning effect.

In addition, the center of the ionization region was located about $4 \mathrm{~mm}$ above the MS axis and ions were extracted by pulsed potentials as high as possible $(+5 \mathrm{kV}$ repeller, $-5 \mathrm{kV}$ extraction grid). A post-acceleration voltage as high as $21 \mathrm{kV}$ was routinely used enabling measurements well into the region above $1 \mathrm{Mu}$. By using a thin $(0.5 \mathrm{~mm})$ laser sheet for ionization a resolution of about 5000 could be achieved. Also this Reflectron MS was built by S. Käsdorf, Munich.

\section{d) Photoionization}

Electron impact ionization (EI) offers an only limited sensitivity for heavier PAHs and light particles. For this reason photo ionization was used in this work despite of its disadvantage that sensitivities can be very much species dependent (see above). An ArF excimer laser was used (Optex or Optex Pro, Lambda Physics, Göttingen) which furnishes $193 \mathrm{~nm}$ photons. At this wavelength PAHs are ionized through 1+1 REMPI (resonance enhanced multiphoton ionization). Tuning of frequencies is not possible as we use a fixed frequency laser. Nevertheless, resonances are possible due to the relatively broad bandwidth of the excimer radiation.

Since nascent particles can be very vulnerable to fragmentation, fluences have to be kept low, i.e. below $1 \mathrm{MW} / \mathrm{cm}^{2}$ and this is significantly below the range regarded as safe with respect to fragment free ionisation of gaseous $\mathrm{PAHs}^{28}$. Consequently, no focussing was used. Instead, after collimation by rectangular apertures $(1 \times 5 \mathrm{~mm}$ or $2 \times 5 \mathrm{~mm}$ wide) the beam was attenuated by a set of calibrated grey filters to obtain fluences in the 0.1 to $1 \mathrm{MW} / \mathrm{cm}^{2}$ range. The laser was typically operated at a an energy of about $1.5 \mathrm{~mJ} /$ pulse to enable efficient control of the laser output. Pulse energies were determined by calibrated energy meters.

\section{e) Setup with a combined IR and UV source}

Motivation for this part of our work was to study LII induced effects on soot. In comparison to earlier experimental versions ${ }^{30}$, this setup has been modified in two regards, inlet system and ion source. See Fig.1. The $90^{\circ}$ quartz entrance nozzle (available diameters 0.5, 1 and 1.5 $\mathrm{mm}$, respectively) forms an integral part of a double walled quartz flow reactor. The dimensions of the inner tube are $20 \mathrm{~mm}$ diameter and $120 \mathrm{~mm}$ length. Carrier gas $\mathrm{He}$ is fed through the space between these tubes so that dilution is achieved immediately downstream of the first nozzle. The seal between the reactor and the metal vacuum housing is provided by 
elastomer rings which are positioned at the cooler end of the quartz tube. As a consequence, extra cooling to protect the sealing material becomes obsolete.

The nozzle through which the beam is formed is indicated in bold in Fig. 1. It is followed by a skimmer (1 mm throat).

By using a dichroic mirror the fundamental of an IR laser (Brilliant B, Quantel, France) was fed co-axially to the UV beam to the ion source (see Ref. 33 for details). Typical fluences for the IR were between 0.5 and $10 \mathrm{~mJ} / \mathrm{mm}^{2}$ and for the UV $(193 \mathrm{~nm})$ around $0.5 \mathrm{MW} / \mathrm{cm}^{2}$, corresponding to $0.05 \mathrm{~mJ} / \mathrm{mm}^{2}$. These data were obtained using calibrated energy meters.

The entrance aperture of the extraction electrode of the mass spectrometer was widened in vertical direction $(9 \times 12 \mathrm{~mm}$ instead of $3 \times 12 \mathrm{~mm})$ to allow for a wider vertical range of ionizing positions. This is obviously on the expense of mass spectrometric resolution.

\section{Results}

\subsection{Measurements using the mobile apparatus}

\section{a) Nascent particles from flat premixed flames}

Measurement in a time-of-flight mass spectrometer furnishes mass spectra as ion numbers within a given time interval and as a function of time-of-flight. As described in Ref. 29 these raw data can be transformed into signals as a function of mass (particle mass distribution function, PMDF). By so doing the distribution curves change their shapes because the mass interval is not a linear function of the time interval. The same holds when in a further step PMDFs are transformed into particle size distribution functions (PSDF). For this transformation the density is needed $\left(\rho=1 \mathrm{~g} / \mathrm{cm}^{3}\right)$. All three methods of displaying data are equivalent. While ion numbers as a function of time represent original data, for some purposes it may be more appropriate to show the mass dependence and for other ones the size dependence. In this paper all three methods are used.

As the test case a so-called McKenna burner was used at atmospheric pressure. Here the premixed combustion gases are driven through a water-cooled porous disc of $6 \mathrm{~cm}$ diameter. The upper part of the flame was stabilized by a steel plate. The combustion gases were $\mathrm{C}_{2} \mathrm{H}_{4}$ (grade 3.0) and compressed air cleaned by an oil filter. The cold gas flow velocity was typically $5.2 \mathrm{~cm} / \mathrm{s}$. Gas flows were measured using flow controllers (Tylan) calibrated by means of a coriolis flow meter (Danfoss).

Particle size distribution functions (PSDF) as a function of the height of the vertical probe above the burner are shown in Fig. $2\left(\mathrm{C}_{2} \mathrm{H}_{4}\right.$-air flame, $\left.\mathrm{C} / \mathrm{O}=0.62, \mathrm{v}_{\mathrm{u}}=7.5 \mathrm{~cm} / \mathrm{s}\right)$. A similar set of profiles has been published in Ref. 29. In this diagram the hump for equivalent diameters below $1 \mathrm{~nm}$ is caused by unresolved gas phase peaks. The message of Fig. 2 is that nascent nanoparticles occur in two modes, called A and B, respectively. This bimodality is most pronounced at low heights above the burner. When the height is increased both modes grow in intensity. With regard to mass the second mode seems to remain essentially unchanged whereas the first mode becomes heavier and heavier. As a result, the valley between both modes gets blurred and is eventually completely lost.

A similar behaviour was found when $\mathrm{C} / \mathrm{O}$ was varied for a fixed height. Here, pronounced bimodality could only be observed in a narrow $\mathrm{C} / \mathrm{O}$ window (see Ref. 29). As will become clear when reporting results obtained at low pressure flames, there are no fixed size ranges which can be attributed to these two modes. They can, however, be further differentiated through their temperature dependence, their ionization behaviour and their reactivity as to be discussed below. 


\section{b) Temperature dependence of the particle size distribution function (PSDF)}

PSDFs of nascent nanoparticles are very much dependent on the $\mathrm{C} / \mathrm{O}$ ratio as was shown in our previous work ${ }^{29}$. Consequently, in an attempt to study the influence of flame temperature the $\mathrm{C} / \mathrm{O}$ ratio of the unburned gas was kept constant, $\mathrm{C} / \mathrm{O}=0.62$. A first experiment was carried out as a reference using an ethylene air flame, $\mathrm{v}_{\mathrm{u}}=5.7 \mathrm{~cm} / \mathrm{s}$, see blue profiles in Fig. 3. Assuming the same mass spectrometric sensitivity for both modes one obtains for the relative abundances $\mathrm{A} / \mathrm{B}=3.7$.

In the next step air was replaced by oxygen leading to a hotter flame. Unfortunately, for reasons of flame stability the velocity of the unburned gas had also to be changed $\left(v_{u}=4.5\right.$ $\mathrm{cm} / \mathrm{s}$ ), so that the results of both experiments are not strictly comparable. Qualitatively it is obvious from the red profile in Fig. 3 that the sizes of A and B, respectively, remain essentially unchanged. With regard to intensity, however, B wins on the expense of A leading to a ratio $\mathrm{A} / \mathrm{B}=0.57$. This is consistent with the interpretation of $\mathrm{B}$ formation as a high temperature mechanism ${ }^{23}$. Unfortunately, we did not have the means to determine the temperature experimentally. The calculated adiabatic flame temperatures are $1974 \mathrm{~K}$ for the ethylene air flame and $3078 \mathrm{~K}$ for the ethylene oxygen flame. For the presented stabilized flames the temperature difference should be smaller.

Interestingly for both experiments there is also a shift in the distribution of gas phase molecules which is beyond the scope of this paper. Therefore, it is not only temperature but also the gas phase precursors determining which nanoparticle mode is predominantly generated.

\section{c) Ionization order and fragmentation}

In PIMS one uses fluences of the ionizing beam as high as possible to get strong signals, yet not high enough to induce fragmentation or saturation. Consequently it is wise to determine the dependence of the ion signal on the laser fluence prior to any routine measurement. By doing so one obtains the so-called ionization order $n$ which is defined $a^{28}$

$$
\mathrm{I}_{\mathrm{m}}^{+}=\text {const } \cdot\left(\mathrm{P}_{\mathrm{L}}\right)^{\mathrm{n}}
$$

where $\mathrm{I}_{\mathrm{m}}^{+}$denotes the intensity of the ion signal at mass $\mathrm{m}$ (which ideally should contain only one constituent), $\mathrm{P}_{\mathrm{L}}$ denotes the power density of the laser pulse. $\mathrm{n}$ is determined as slope in an $\lg \left(\mathrm{I}_{\mathrm{m}}^{+}\right)$vs. $\lg \left(\mathrm{P}_{\mathrm{L}}\right)$ plot. This was carried out for $\mathrm{A}$ and $\mathrm{B}$ particles independently and the results are shown in Figs. $4 \mathrm{a}$ and $4 \mathrm{~b}$ (see also Ref. 34). For A particles, the straight portion of the signal vs. fluence curve is very short and indicates a slope close to 2 . In addition, beyond about $0.2 \mathrm{MW} / \mathrm{cm}^{2}$ there is a significant deviation from the straight line hinting to fragmentation. This then occurs for A particles already at very low values and this obviously impairs their measurement.

For B particles not only the fragmentation threshold is higher by a factor of about 10 . In addition, for the used wavelength of $193 \mathrm{~nm}$ corresponding to $6.3 \mathrm{eV}$ the ionization mechanism seems to be different as reflected by an ionization order close to 1 . In the absence of interfering effects the ionization order corresponds to the number of photons required for the ionization process in question. Therefore we assume as to be discussed later in more detail that using $193 \mathrm{~nm}$ photons mode B can be ionized in a single step whereas A requires two photons for ionization.

\section{d) PSDF profiles inside and outside the flame}


For the measurements shown in Figs. $5 \mathrm{a}$ and $5 \mathrm{~b}$ an ethylene air flame $\left(\mathrm{v}_{\mathrm{u}}=5.2 \mathrm{~cm} / \mathrm{s}, \mathrm{C} / \mathrm{O}=\right.$ 0.7 ) was used surrounded by an $\mathrm{N}_{2}$ shroud and with a visible flame edge at $40 \mathrm{~mm}$. The nanoparticle profiles are similar to Fig. 2, yet a much larger range in terms of Hab is covered. In addition, particle mass distributions (PSMF) are reported rather than PSDFs as in Fig. 2 and this is the main reason for the different shape of the profiles relatively to Fig. 2. As a function of $\mathrm{Hab}$ one notes a continuous growth predominantly of the A mode leading to apparently monomodal profiles. Maximum signals are obtained for $\mathrm{Hab}=30 \mathrm{~mm}$. Beyond this position a small intensity loss is observed within the flame. This consumption of nanoparticles continues outside of the flame as shown in Fig. 5b. However, even at a height of $140 \mathrm{~mm}$, i.e. $100 \mathrm{~mm}$ outside of the flame the nanoparticle profile is still measurable, yet it has changed its shape. The B mode becomes clearly visible at heights around 90 to $140 \mathrm{~mm}$ whereas the excess of $A$ has disappeared probably because of reaction with $\mathrm{O}_{2}$ due to an incomplete shielding by the $\mathrm{N}_{2}$ shroud. Interestingly it is predominantly A that reacts. B remains essentially unchanged and the apparent bimodal behaviour is restored.

In a separate experiment ${ }^{36}$ the $\mathrm{N}_{2}$ shroud surrounding the flame was replaced by air. Effects on the profiles inside of the flame were found only in the vicinity of the flame edge. Outside of the flame, however, the nanoparticles were rapidly consumed to leave a narrow background, probably due to B mode particles.

\section{e) Behaviour on a cloth filter}

The larger reactivity of A particles was also found during tests of various filters. This work was carried out in preparation of engine experiments. Measurements in a soot-laden atmosphere may be impaired by soot deposits which form on the walls of the sampling line and can lead to serious memory effects. This problem was particularly encountered during measurements behind a Diesel engine (see subsequent section). For its minimization we carried out experiments using filters with several filter media. The position of the filter was 25 $\mathrm{cm}$ downstream of the sampling nozzle. Goal was to cope with the following requirements, small pressure drop, sufficient temperature resistivity, efficient trapping of soot, only small effects on nanoparticle distribution functions.

Best results were achieved using a thin $(0.2 \mathrm{~mm})$ cotton disc. The data are shown in Fig. 6 in time-of-flight display. The upper curve is a spectrum with the filter case empty, the lower two curves were measured with the filter inserted and in a time interval of 10 minutes. One notes that both nanoparticle modes were trapped to some extent, which is larger for the A mode. The maxima of the PSDFs remain essentially the same.

Furthermore, the similarity of the two lower curves demonstrate that during 10 minutes not enough soot was trapped on the filter to change its efficiency. Consequently, during the engine measurements we took care, that the filters were replaced about every 8 to 10 minutes.

\section{f) Engine experiments}

For these measurements we had access to a $100 \mathrm{~kW}$ passenger car Diesel engine mounted on a dynamometer at the University of Aachen (RWTH). The 2.21 four-cylinder in-line engine was equipped with a common-rail direct injection system and an exhaust turbo charger. The engine control system of the manufacturer was replaced by an own control box so that engine conditions could be varied in a broad range. Commercial Diesel fuel and lube oil were used. 
Two lines were used for mass spectrometric sampling, one directly behind the charger (called "turbine" in Fig. 7), i.e. upstream of the oxidation catalyst (DOC) and the other one behind the catalyst. The lines consisted of heated electro-polished stainless steel tubes of $6 \mathrm{~mm}$ id. They were connected to $1 \mathrm{~mm}$ stainless steel nozzles that protruded well into the exhaust gas flow. These lines could be closed by wide bore solenoid valves and were opened only during the measurement intervals to minimize deposition of soot. For this same purpose filters were used as described in the previous section. They were positioned $25 \mathrm{~cm}$ downstream of the sampling nozzle.

The dependence of PSDFs on the fuel air stoichiometry is shown in Fig. 7. Normally a Diesel engine is operated at lean or even very lean conditions. Stoichiometric conditions $(\Phi=1)$ are therefore called "rich" as in Fig. 7. Here one notes the bimodal distribution already known from flames. The B mode extends well in the region of mature soot $(>10 \mathrm{~nm})$ without any gap. For lean conditions $(\Phi=0.5)$ the particle concentrations were found to be nearly 3 orders of magnitude lower and for sizes exceeding $5 \mathrm{~nm}$ the noise level was approached. For these two operation conditions the efficiency of the catalytic oxidation converter was examined by measuring before and behind the converter as shown in Fig. 8. For comparison a bimodal nanoparticle profile is included as obtained from a laboratory flame before the engine measurement campaign. Fortunately the same flame profiles were found after this campaign indicating that the instrument sensitivity did not change during the engine measurements. Consequently, the flame profiles could be used for calibration, the calibration procedure being described in detail in Ref. 29). The integrals of these profiles represent total ion numbers. Their comparison led us to the following figures.

The integrated profile yields for the rich case an initial concentration of $3.7 \cdot 10^{10} \mathrm{~cm}^{-3}$ upstream of the converter. Only $6 \%$ of these particles survive the catalytic converter leading to emissions of $2.410^{9} \mathrm{~cm}^{-3}$. For the lean case we find only $110^{8} \mathrm{~cm}^{-3}$ particles. Surprisingly, these survive the catalytic converter virtually unaffected.

For completeness we mention that for the rich case also the dependence on laser fluence was checked. The result is that particles of lower mass show a significantly stronger fluence dependence than those of higher mass. This again supports the concept of two co-existing types of particles. Unfortunately, for these engine emissions no clear separation of these modes was possible and hence no unambiguous deduction of a number of the ionization order.

\subsection{Measurements using the stationary apparatus}

\section{a) PSDFs in a broad $\mathrm{C} / \mathrm{O}$ range}

These measurements shown in Fig. 9 were carried out behind flat ethylene flames burning at low pressure of about 110 mbar and using $\mathrm{O}_{2}$ as oxidizer rather than air, $\mathrm{v}_{\mathrm{u}}=10.6 \mathrm{~cm} / \mathrm{s}$, Hab $=40 \mathrm{~mm}$. Here we benefited from the two-nozzle inlet system (see Experimental) as the lower $1 \mathrm{~mm}$ nozzle provided sufficient sensitivity also in the $\mathrm{C} / \mathrm{O}=0.9$ case when particle concentrations were very low. On the other hand also for the flame nozzle a relatively wide throat could be chosen so that clogging by soot was not a problem even for $\mathrm{C} / \mathrm{O}=1.1$. Such rich flames are normally avoided by flame researchers because of the clogging problem. Consequently it is our special inlet system which allowed to map out nanoparticle profiles in a wide $\mathrm{C} / \mathrm{O}$ range with concentrations covering a range as wide as $10^{4}$.

The vertical spikes in the right half of Fig. 9 are artefacts caused by the high-gain (1:200) preamplifier (Ortec) in combination with a low threshold of the subsequent discriminator used for ion counting. The spikes obviously do not influence the shape of the profiles. This combination of amplifier and discriminator was used as it facilitates the measurement of profiles at low concentrations. 
One notes in the entire $\mathrm{C} / \mathrm{O}$ range of Fig. 9 the $\mathrm{A}$ and $\mathrm{B}$ distribution functions known from Fig. 3 with $\mathrm{B}$ exceeding $\mathrm{A}$ as normally found in $\mathrm{C}_{2} \mathrm{H}_{4}-\mathrm{O}_{2}$ flames. With increasing $\mathrm{C} / \mathrm{O}$ values the valley between becomes blurred and eventually disappears for $\mathrm{C} / \mathrm{O}=1.1$. The diameter ranges of $\mathrm{A}$ and $\mathrm{B}$, respectively, are slightly different from those found in normal pressure flames.

For $\mathrm{C} / \mathrm{O}=1.0$ a third hump develops at diameters around $6.7 \mathrm{~nm}$. In mass display (PMDF, Fig. 9a; same raw data as Fig. 9) this hump shows up as a weak shoulder at twice the mass of $\mathrm{B}$ and is therefore interpreted as a coagulation product.

Another interesting issue is the transition from mode $\mathrm{B}$ to soot. At $\mathrm{C} / / \mathrm{O}=0.95$ and for the $\mathrm{Hab}$ value of this experiment $(\mathrm{Hab}=40 \mathrm{~mm})$ we observe only very small signals for sizes $>$ $6.5 \mathrm{~nm}$, so that for this $\mathrm{C} / \mathrm{O}$ region essentially nanoparticles are found and only small concentrations of mature soot. For higher $\mathrm{C} / \mathrm{O}$ values this situation changes completely. The measured soot levels increase significantly and at $\mathrm{C} / \mathrm{O}=1.1$ we observe even an increase in the PSDF for sizes $>11 \mathrm{~nm}$. This means that there is a gradual and continuous transition from mode $\mathrm{B}$ to mature soot.

The light mode ranging between 1 and $2 \mathrm{~nm}$ seems to be particularly important for very low $\mathrm{C} / \mathrm{O}$ values. This mode is termed B' and will be discussed in Section 3.2.c).

Finally, we want to emphasize that Figs. 9 and 9a are derived from the same raw data. Their different appearance is for 3 reasons. (i) The range of the abscissa is different as $130 \mathrm{ku}$ correspond to only $7 \mathrm{~nm}$. (ii) Fig. 9 uses a log scale for the ordinate. In Fig. 9a it is in linear scale. (iii) Most important, in diameter display (Fig. 9, PSDF) the lower parts of the plot appear expanded so that B' peaks are clearly discernible. In mass display (Fig. 9a, PMDF) these portions of the spectrum are compressed rendering B' merely as spikes.

Note that spectra in diameter display (PSDF, Fig. 9 for example) ressemble very much to time-of-flight spectra, i.e. our raw data (see Fig. 10). In both cases the lower portions of the graphs is expanded relative to ion vs. mass plots (Fig. 9a, PMDF).

\section{b) Variation of the laser fluence}

For a better characterization of the A and B modes the laser fluence was varied. The results are shown in Fig. 10. It is seen that upon increasing the pulse energy by constant factors the profiles referring to B shift by equal amounts (note: log plot). For the A mode, by contrast, there is a development from a tiny hump nearly hidden in the rising flanc of B for a pulse energy of $0.25 \mathrm{~mJ}$ up to a well developed maximum at $4 \mathrm{~mJ}$. This means that the dependence on the fluence is more pronounced for the A mode than for the B mode and this supports the view of two co-existing nanoparticles modes. It was not attempted to extract data for the ionization order of $\mathrm{A}$ because of the difficulty to separate the small A contribution from the large background of B in the case of low fluences. For B, however, the integration of the profiles is straightforward, and the results are shown in Fig. 10a. The slope of the straight line is 0.8 , indicating an ionization order of 1 . As to be described in the next section, this ionization order is associated with layered structures consisting of graphite-like sheets. A possible explanation for the deviation from 1 might be that a small fraction of B enters the mass spectrometer as "natural" ions. For a separation of such an effect a wider range of fluence variation would be required. This range was in the present case restricted on the high side because of fragmentation and on the low side by the sensitivity of the mass spectrometer.

\section{c) Analysis of particle spectra at lower masses and using higher resolution}


We now turn to the low mass section of the profiles denoted by B' in Fig. 9. The analysis of particle mass spectra in this mass range was carried out by Happold ${ }^{36}$ several years ago. At that time, neither the high repeller and extraction voltages that are now in use, were available to Happold nor the high post-acceleration voltage which provides sufficient multiplier gain even at very high masses. As a consequence he was unable to detect masses beyond some $1000 \mathrm{u}$ and so could not see the full picture emerging from Fig. 9.

An important finding of Happold's work was that photo-ionization (193 nm) spectra of flame gases did not disappear at masses somewhat higher than $300 \mathrm{u}$ as was expected from flame spectra reported in the literature ${ }^{37}$. The $193 \mathrm{~nm}$ spectra rather extended into the range of several $1000 \mathrm{u}$ and this occurred in a wave-like form (see Fig. 11). When, however, the ArF laser gas $(193 \mathrm{~nm})$ was replaced by $\mathrm{KrF}(248 \mathrm{~nm})$ the spectra changed to the form familiar from the literature (shown in the inset of Fig. 11), i.e. conventional gas phase spectra. The idea was straightforward that the "new" peaks in Fig. 11 which are found using $193 \mathrm{~nm}$, are related to particles and that these differ from gas phase peaks with regard to the ionization mechanism as they show up only at the higher photon energy.

In an analysis well documented in the literature ${ }^{23,30}$ it was found that peaks referring to particles show an ionization order of 1 . The gas phase peaks, by contrast, follow an ionization order of 2 as to be expected from the fact that ionization potentials of PAHs are well above the energy of $6.3 \mathrm{eV}$ which is provided by $193 \mathrm{~nm}$ photons. For the particles, in turn, a decrease of the IP (actually work function) has to occur making one-photon ionization possible when $193 \mathrm{~nm}$ photons are used. Such a shift is found as a result of $\pi-\pi$ interaction in aromatic systems when PAHs are composed to form stacks. A well-known example is graphite with a work function of only $5 \mathrm{eV}^{38}$. This arrangement is also consistent with the wave-like structure of the spectra shown in Fig. 11. Our current interpretation is that the tiny crystallites which form the B' particles, actually are precursors to $\mathrm{B}$, i.e. that $\mathrm{B}$ is a coagulation product of B'. This view is supported by the fact that B' particles are particularly significant when $\mathrm{B}$ is low.

\section{d) Combined IR and UV experiments}

The purpose of these experiments was to find out which fragments are formed when soot is irradiated by IR light $(1064 \mathrm{~nm})$ as is in use when particle sizes are determined by LII (laser induced incandescence). To this end the ionization source of our mass spectrometer was equipped with an additional IR laser (see Fig. 1). The purpose of the UV laser was to ionize IR induced fragments which were assumed to be uncharged. A more detailed account will be given in Ref. 33. For the sake of brevity only two figures referring to this work are given here. In Fig. 12a one recognizes the familiar distribution of A and B when only UV light is irradiated. These particles are nearly completely lost when additional IR light is irradiated even at moderate fluences ( 1 to $3 \mathrm{~mJ} / \mathrm{mm}^{2}$ ). Furthermore, a "new" particle mode is formed, hence called $\mathrm{N}$, which by its intensity suggests that it is not only formed from fragments of A and $\mathrm{B}$, but mainly from soot which due to its mass is outside the mass range of Fig. 12a. The amount of destruction of A and B is more clearly visible in linear display (Fig. 12b). Upon IR irradiation A nearly disappears to form a small hump superimposed to the tail of $\mathrm{N}$. The destruction of B is even more complete.

A further and up to now unexplained finding is that when the IR is on, no further UV is needed to detect ions, i.e. IR alone leads to ionization. Generally the profiles referring to "IR only" and those of "IR+UV", respectively, nearly coincide. Only for the A mode and low IR fluences there is an exception as upon additional UV irradiation slightly more A particles are found. This means that some fraction of A must have survived the IR light as neutrals and became ionized through UV. 
In an attempt to find out the identity of $\mathrm{N}$ the mass spectrometer was operated at high resolution to obtain the spectra of Fig. 13a. They look somewhat similar to those of Happold, Fig. 11. The peaks referring to "UV only", i.e. B' particles are shown in black. When IR is switched on (IR only) new spectra are generated of which two examples are shown in Fig. 13. For a fluence of $1 \mathrm{~mJ} / \mathrm{mm}^{2}$ and shown in red we found a peak distribution with a maximum around $2000 \mathrm{u}$. Further and preliminary measurements using a different IR laser showed that these maxima shift to even higher massen when fluences below $1 \mathrm{~mJ} / \mathrm{mm}^{2}$ are used. At higher fluences $\left(10 \mathrm{~mJ} / \mathrm{mm}^{2}\right.$, blue), however, the distributions shift to lower mass values and seem to become even bimodal. An interesting and unexpected result is that with lower fluences larger particles are generated.

Actually, in the gas phase spectra small $\mathrm{C}$ clusters were found, $\mathrm{C}_{3}$ to $\mathrm{C}_{17}$. For the IR generation of these small clusters fluence thresholds between 2 and $3 \mathrm{~mJ} / \mathrm{mm}^{2}$ were measured (see Ref. 33). For the large clusters, by contrast, shown in Fig. 13a we were unable to determine a threshold as stable laser operation at the required low fluences was impossible. Therefore, we can presently only say that the generation of large clusters, $C_{x}(50<x<250)$ requires much less energy than generation of small clusters, $C_{y}(3<y<17)$.

For an identification of the nature of $\mathrm{N}$ the spectra of Fig. 13a were expanded to yield Fig. $13 \mathrm{~b}$. The peaks in question (blue and red) show a periodicity of $24 \mathrm{u}$, obviously evennumbered $\mathrm{C}$ atoms with odd-numbered ones between and at lower intensity. Generally the resolution of these spectra is poor so that further structures which are found between the $\mathrm{C}$ signals cannot be interpreted. The black trace, however, which refers to "UV only" shows well resolved peaks. This means that the resolution the mass spectrometer is sufficient. Since the ionization zones for UV and IR are of comparable size, the poor resolution of the IR generated spectra can only mean that these particles possess an initial energy which randomly affects their flight velocity. In principle, such an effect can be minimized using a reflectronTOF. Research towards this goal is underway.

\section{Discussion}

\section{a) Bimodality of transition particles}

In the earlier literature it was generally assumed that nascent soot particles exist in a single $\operatorname{mode}^{39,40}$ and that consequently a PSDF including soot would show a bimodal form, nascent particles forming the first mode and soot the second one ${ }^{14,41}$. Actually the particle features advocated by D'Alessio and coworekes ${ }^{39}$ on one hand and Dobbins et al. ${ }^{40}$ on the other are very different and in part even contradicting (see more detailed discussion in Ref. 34). For instance "Dobbins particles" were reported to show micro-crystallinity ${ }^{42}$ and this was explained through stacks of larger PAHs ${ }^{43}$. These systems absorb in the UV as well as in the visible. "D'Alessio particles", by contrast, were reported to absorb only in the UV and to show complete transparency in the visible. This led to the conclusion that they are composed of aromatic subunits with no more than 2 to 3 rings and which are tied together by aliphatic bonds or bridges ${ }^{44}$.

This led Gonzalez Baquet and coworkers ${ }^{34}$ to the assumption that nanoparticles occur in two modifications of either the "D'Alessio type" or the "Dobbins type". Indeed these modifications co-exist and consequently bimodal PSDFs of soot precursors could be shown in flames, albeit in a limited $\mathrm{C} / \mathrm{O}$ range $\mathrm{e}^{29,34}$. This bimodality of soot precursors was found by other researchers, too ${ }^{45,46}$. Very recently bimodality was demonstrated by using a so-called particle mass spectrometer (PMS) behind flat atmospheric ethylene air flames ${ }^{25}$. Although the measured PSDFs show a clearly bimodal shape, their intensity distributions look somewhat unfamiliar as the B mode always dominates. This may be attributed to differences in 
ionization efficiencies caused by differences in ionization potential. Unfortunately, the ionization mechanism for these "natural" flame ions is not yet clear"

\section{b) Structure of nanoparticles}

For reasons to be outlined below we identify our A mode as "D'Alessio particles". On the grounds of their transparency in the visible it was postulated for these particles that they should consist of aromatic subunits which comprise no more than 3 fused aromatic rings. This led Violi and coworkers ${ }^{47-52}$ to develop a mechanism starting with radical formation of cyclo penta compounds (cp) such as acenaphthylene or acephenanthrylene. Radical formation is on the $\mathrm{cp}$ bridge through destruction of the double bond. At this site aromatic molecules such as naphthalene can add. By repetition, this sequence is thought to furnish very large molecules. The specific feature of the proposed mechanism lies in the fact that $\mathrm{cp}$ radicals are reported to form long-lived complexes through resonance stabilization. Since addition of further aromatic compounds is via a $\sigma$-bond these systems contain only small aromatic subunits and are no longer planar. Instead, very floppy and open structures were obtained by $\mathrm{Violi}^{52}$ through model calculations. Two resulting structures are shown in Fig. 14. They are characterized through many edge sites and a complete lack of rigidity and periodicity. Therefore they are regarded as a giant molecules. It should be noted, however, that up to now these structures could not be observed experimentally, e.g. by mass spectrometry.

For the B particles an entirely different picture emerges if one adopts our interpretation that B' particles (see Fig. 9) are precursors to B and that their properties are preserved. From an $\mathrm{H} / \mathrm{C}$ analysis Happold ${ }^{23}$ found that the building elements of $\mathrm{B}$ ' are pericondensed PAHs characterized through a minimum of edge sites. This is consistent with the findings of Dobbins et al. $^{43}$. From the periodicity of the mass spectra Happold derived a polymer-like structure of these PAHs. Finally, the decrease of ionization energy which is reflected by the shift of the ionization order from 2 to 1 led to the conclusion that the "mers" are arranged in stacks rather than chains. This is fully consistent with the difference in IP between gaseous PAHs $(7$ to $8 \mathrm{eV})$ and graphite $(5 \mathrm{eV})$, respectively. It is also consistent with the crystallinity found by Dobbins for nanoparticles ${ }^{42}$. In particular he reported lattice constants for these particles to be very close to graphite. From the linewidth of Bragg refexions average numbers of layers could be derived to be below $10^{42}$ and this is also consistent with Happold's spectra. The formation mechanism was shown ${ }^{36}$ to be a high temperature mechanism (see also Fig. 3). In conclusion we identify our B mode as "Dobbins particles", i.e. micro-crystallites exhibiting a minimum of edge sites and showing rigidity as well as periodicity. The resulting stability is also reflected by the relatively high fragmentation threshold above some $\mathrm{MW} / \mathrm{cm}^{2}$ (see Figs. $4 \mathrm{~b}$ and a) which is comparable to those of non-substituted PAHs ${ }^{28}$. For the floppy Astructures as shown in Fig. 14 the fragmentation threshold was found to be a factor of 10 lower.

\section{c) Behaviour of nanoparticles. Growth, reactivity, coagulation}

The nanoparticle properties described above influence also their behaviour with regard to growth, reactivity and coagulation. Concerning growth it is obvious that the many edge sites of the A-mode favour addition of gas phase species. This is consistent with our observation of A as growth species (see Fig. 2 and Ref. 29). B in turn with its much fewer edge sites should be more stable, in accord with Fig. 2. 
With regard to reactivity, it is particularly the reactivity towards $\mathrm{O}_{2}$ and coagulation which determine the fate of nanoparticles once released in the atmosphere. Surprisingly, no direct investigations exist on these reactions. We also can only provide qualitative observations.

One of them is the behaviour of particles on thin cotton filters $(0.2 \mathrm{~mm})$. In Fig. 6 it can be seen that both modes are trapped, the A-mode however, with higher efficiency. In view of the many edge-sites of A this is not surprising although it is at variance with reports of D'Alessio and coworkers ${ }^{44}$. They point out that these particles "are characterized by a very low coagulation rate so that they can easily escape from filters and trapping systems".

Concerning reactivity towards $\mathrm{O}_{2}$ our particle profiles inside and outside of flames (Fig. 5) suggest that $\mathrm{A}$ reacts much faster with $\mathrm{O}_{2}$ than $\mathrm{B}$ does. As this reaction provides a potentially important nanoparticle sink direct measurements would be very useful.

The same is true with regard to coagulation. Here a puzzling discrepancy exists between Aparticles and larger ones, especially soot. For the latter sticking coefficients of 1 are normally assumed so that coagulation occurs in the kinetic limit. For A-particles, by contrast, collision efficiencies between $10^{-3}$ and $10^{-2}$ are reported ${ }^{44,53}$ so that coagulation is extremely slow. To the best of our knowledge no direct measurements exist on this important reaction. In preliminary direct measurements ${ }^{54}$ using an isothermal flow reactor with movable particle inlet we measured particle profiles as a function of injector position and found a considerable coagulation for a mixture of $\mathrm{A}$ and $\mathrm{B}$ particles (probably mostly $\mathrm{A}$ ). These measurements, however, lacked from an accurate concentration calibration of nanoparticles so that no absolute rate coefficients could be determined.

\section{d) Nanoparticles behind engines}

To our knowledge these are the first reported mass spectrometric measurements of nanoparticles behind engines. In a first attempt ${ }^{29}$ we failed to detect nanoparticles behind a carburetted gasoline engine. More precisely an upper limit was derived to be in the order of $20 \mu \mathrm{g} / \mathrm{m}^{3}$. This translates to $6 * 10^{9}$ particles $/ \mathrm{cm}^{3}$ if tiny monodisperse particles of only $2000 \mathrm{u}$ (corresponding to $1.8 \mathrm{~nm}$ ) are assumed as a model. This number density is below the values reported recently by Sgro et al. ${ }^{55}$. They carried out measurements behind 2004 model vehicles with CI and SI engines. Several experimental methods were used and absolute nanoparticle concentrations could be derived from extinction measurements. For the two gasoline engines they report $150 \mu \mathrm{g} / \mathrm{m}^{3}$ and $60 \mu \mathrm{g} / \mathrm{m}^{3}$, respectively, for the $10: 1$ diluted exhaust. Using the lower value and assuming $2 \mathrm{~nm}$ (i.e. $4000 \mathrm{u}$ ) for the particles, a number density of about $1 * 10^{11} \mathrm{~cm}^{-3}$ can be derived for the undiluted case. From their paper it is not clear whether the examined gasoline engines used injection systems. For newer engines this is probably the case and it would explain the higher particle load. For carburetted engines, however, the incylinder mixture can be assumed to be homogeneous. The mixture strength should be about stoichiometric, in any case well below the sooting threshold so that no nanoparticles are to be expected.

The detection of nanoparticles behind a strongly sooting $(\Phi=1)$ Diesel engine (see Fig. 7) is new as it was carried out with mass spectrometry. One should, however, clearly see that this operation mode is untypical for a Diesel engine. Therefore, the particle number densities derived from the profiles in Fig. 8, are not discussed here.

For the more relevant lean case we found particle number densities around $1 \cdot 10^{8} \mathrm{~cm}^{-3}$. These particles have a mean diameter of about $2.5 \mathrm{~nm}$, leading to a total nanoparticle emission of 1.2 $\mu \mathrm{g} / \mathrm{m}^{3}$. This is very low in comparison to the value of Sgro et al. ${ }^{55}$. They report $180 \mu \mathrm{g} / \mathrm{m}^{3}$ for the diluted case, i.e. even $1800 \mu \mathrm{g} / \mathrm{m}^{3}$ for the undiluted case. Although our value appears to be very low on a weight basis it is significant on a number concentration basis. Furthermore one has to keep in mind that these particles are not affected by the oxidation catalyst. This is 
inferred from the fact, that particle profiles upstream and downstream the catalyst cannot be distinguished, see Fig. 8. So one has to assume that they are completely released into the atmosphere.

\section{e) Relation to soot}

Purpose of this short section is to discuss how the pictures developed so far for nanoparticles could be used in a soot model. Ishiguro and coworkers ${ }^{56}$ examined Diesel soots by TEM analysis and further chemical methods. The soots were generated in a broad range of engine operation conditions. For all these soots a common picture has emerged which is shown in Fig. 15 and described as follows. In Diesel soot two parts co-exist "with different formation processes". (i) A platelet model with crystallites containing several layers of planar carbon sheets that are oriented concentrically in the soot particle. (ii) An inner core containing fine particles with a spherical nucleus and surrounding carbon networks with a bending structure indicating that they contain many five-membered rings. When the soot was treated with nitric acid only the inner core was dissolved. Obviously, due to the instability of its structure it could be easily oxidized.

The idea is tempting to assume that the crystallites described by Ishiguro originate from Bparticles and to assign the amorphous cores with their many five-membered rings as Aparticles. How does this fit into Fig. 9? First of all, we note from Fig. 10 that A and B are clearly marked as different species through their different ionization behaviour. The Bcrystallites appear at masses with maxima between 50 and $60 \mathrm{ku}$. For an average mass of a basal plane (of these crystallites) we get masses between 2500 and $3000 \mathrm{u}$ (see next section). Consequently one would need 20 layers for a crystallite of the required mass. This seems a very high number also in comparison to numbers (slightly below 10) quoted by Chen and Dobbins $^{42}$. Two crystallites each with 10 layers on average would add to the required mass, perhaps arranged in a T-like shape in order to reduce strain energy. In any case the mass around $60 \mathrm{ku}$ seems to belong to a particularly stable configuration. Otherwise it would not show up as a clear maximum and formation of a dimer at $120 \mathrm{ku}$ would not be plausible.

No such dimerization can be expected for $\mathrm{A}$ as the A structures are much less defined although in terms of mass they appear in a fairly distinct region.

One also notes from Fig. 9 that there is no clear separation between B and primary soot, the latter being characterized by diameters around $10 \mathrm{~nm}$ (see e.g. Ref. 57) and masses in the range between 500.000 and 1 Million $\mathrm{u}$. Rather, for sufficiently high $\mathrm{C} / \mathrm{O}$ ratios, there is a smooth and continuous transition from B to soot. To build up the masses of primary soot between 10 and 20 of B-crystallites would be required and hence a large amount of strain energy unless some A-particles would sit in the core and act as a kind of glue. This actually is very close to the picture developed by Ishiguro et al..

\section{f) Interpretation of the LII experiment}

According to the finding of D'Alessio and coworkers ${ }^{44}$ that A-particles do not absorb in the visible and IR, no effect of IR radiation on A-particles, yet a major one on B or B-like regions in soot is to be expected. This is seen in Fig. 12 b. Upon IR irradiation B is destroyed to a higher extent than A. Also, upon IR, relative to B more neutral A particles survive which can be ionized by additional UV. That we get ions at all in the "IR only" mode is discussed in the section to follow.

The view of IR being absorbed in B-like regions also explains the rigid structure of the spectra in Fig. 13a. These fullerene-like spectra are interpreted as basal planes of the 
crystallites which form the B-regions. A reason for this interpretation is provided by the measurement of fragmentation thresholds. Through variation of the laser fluence we found for small clusters $C_{y}(3<y<17)$ thresholds between 2 and $3 \mathrm{~mJ} / \mathrm{mm}^{2}$ (more details will be given in Ref. 33) and this is well in accord with data for gas phase species listed in the present literature (see Ref. 58 and references therein). For the generation of the large clusters of Fig. $13 \mathrm{a}, \mathrm{C}_{\mathrm{x}}(50<\mathrm{x}<250)$, however, we were unable to deduce a lower fluence threshold, which therefore has to be significantly below $1 \mathrm{~mJ} / \mathrm{mm}^{2}$. In a second experiment employing a different type of IR laser we observed fragmentation clusters to extend well in the region of $5000 \mathrm{u}$ when fluences around $0.5 \mathrm{~mJ} / \mathrm{mm}^{2}$ were used. At first glance it seems to be completely unreasonable that the generation of large clusters is "cheaper" than generation of small ones. If one bears in mind that lattice planes of B-crystallites are bound by van-der-Waals forces the explanation is straightforward. Cleavage of basal planes just requires the weak van-der-Waals forces to be overcome. For the generation of small clusters, by contrast, real chemical bonds have to be broken. This interpretation of $\mathrm{N}$ as basal planes split off from $\mathrm{B}$ leads to the expectation that $\mathrm{N}$ is a rather unstable intermediate. Probably $\mathrm{N}$ was only detectable since this species was formed in the ion source of the mass spectrometer, i.e. detection followed immediately upon formation.

This part of our LII experiment thus supports the view of B being composed of crystallites with planes hold together by van-der-Waals forces and of soot containing B-like structures.

\section{g) Origin and role of ions?}

Upon irradiation of soot with IR in the mass spectrometer we got a lot of fragments that were nearly completely ionized, i.e. they contained only few neutrals so that no signal enhancement was achieved upon additional UV irradiation. Although considerable fluences were used ( 1 to $10 \mathrm{~mJ} / \mathrm{mm}^{2}$ ) a multiphoton ionization can be ruled out. A 1064 photon contains an energy of $1.14 \mathrm{eV}$ so that even for the ionization of a graphite-like B-particle no less than 5 photons would be required. Such a pile-up is highly improbable given the multitude of scavenging processes in a solid state system. Therefore two questions arise. (i) Where do the ions come from and (ii) could they play a role in soot formation.

The most recent work on charged soot was carried out by Maricq ${ }^{59-63}$. In a series of papers he examined the state of soot charge behind various laboratory flames and car engines. The results can be summarized as follows.

- Nanoparticles are found to be neutral.

- Soot appears as neutral or positive or negative charged to about the same fraction $(1 / 3)$. Up to 4 elementary charges per particle have been found in a Boltzmann distribution, i.e. with decreasing probability.

- The ionization mechanism is thought to be through chemiions which attach to soot.

These findings are only partly compatible with our results shown in Fig. 12. If A and B are neutral as stated by Maricq then $\mathrm{N}$ (which is charged) has to originate solely from charged soot, assuming that the charge remains at the smaller fragment. It is also unexplained why we never saw charged soot (i.e. without additional UV ionization). Actually our measured ions range up to $2 \mathrm{Mu}$ which is well in the region of "young" soot. Should one assume that soot becomes only charged when it is beyond this size?

The other question refers to nanoparticles. Indeed, we observe them only when UV is irradiated indicating that they are formed neutral. This is, however, not fully conclusive as nanoparticles might have lost their charge during their passage through our two-stage inlet system. Nevertheless, the apparent neutrality of nanoparticles seems to be in accord with Maricq. But then it is unclear where the nanoparticle residues get their charge from after irradiation with IR. 
Actually, Wersborg ${ }^{5}$ observed these particles as ions in contrast to Maricq's findings.

A further question is why all our small clusters $\mathrm{C}_{\mathrm{y}}(3<\mathrm{y}<17)$ appeared exclusively as "natural" ions. With regard to this, another model that has also been mentioned by Maricq ${ }^{60}$ is nucleation by gas phase ions. Indeed it was assumed for quite a while (see e.g. Ref. 64) that ion molecule reactions present a more efficient pathway to soot than the currently accepted radical mechanisms. Arguments in favour of such ion models have been thoroughly reviewed by Fialkov ${ }^{65}$. Obviously, our data are by far too scarce to support one or the other of these major soot formation mechanisms. Nevertheless, we found many ions under conditions when no ions were expected. This might be an indication to re-think the old ion molecule model. In fact, it was stated during a recent international workshop by Miller" ${ }^{66}$, "Thus, ionization of clusters for incipient particle stabilization may be relevant to particle growth in flames."

\section{Conclusions}

Through photo ionization mass spectrometry (PIMS) of flame gases, particle size distribution functions (PSDF) of soot precursor particles could be detected. These occur in two modes, termed $\mathrm{A}$ and $\mathrm{B}$.

They are not clearly separated by mass because their mass ranges depend on combustion conditions. They can, however, be distinguished through their different ionization behaviour.

- With $193 \mathrm{~nm}$ photons A exhibits an ionization order of 2 like gaseous organic molecules and an extremely low fragmentation threshold hinting to a very labile structure.

- B shows an ionization order of only 1 and a much higher fragmentation threshold hinting to a stable structure.

Based on an analysis of the ionization properties, an H/C analysis of B (actually B') and supported by further literature data structures were assigned to these nanoparticles.

- A appears in open, floppy structures like the ones proposed by Violi ${ }^{52}$. They are characterized through many edge sites, small aromatic subunits and many 5-membered rings.

- B consists of microcrystallites as described by Dobbins ${ }^{42}$.

The measured behaviour of these particles in terms of growth, reactivity and coagulation is plausible through the quoted structure models.

Both types of particles were found behind a Diesel engine, albeit in small concentrations.

Following a model developed by Ishiguru ${ }^{56}$ a soot primary particle consists of a stable shell region formed by microcrystallites and a more reactive amorphous core. A consistent model is achieved if one assumes the core to consist of A particle(s) and the shell of B.

When a soot-laden molecular beam was irradiated by IR in the ion source of a mass spectrometer, already at very low fluences very large clusters were released. These are interpreted as basal planes of B crystallites.

Surprisingly nearly all IR induced fragmentation products appear as "natural” ions. 


\section{Acknowledgement}

The former DLR thesis students Markus Thierley, Joachim Happold and Tania Gonzalez Baquet helped very much to gather the data described above as did Heinz Pokorny through his permanent technical assistance. This is gratefully acknowledged.

We also acknowledge contributions to the UV+IR experiment from Kevin Thomson, Greg Smallwood and Francesca Migliorini, all of NRC Ottawa, Canada and of our DLR colleagues Klaus-Peter Geigle and Markus Köhler.

Uwe Riedel red this manuscript very carefully. This is also gratefully acknowledged.

\section{References}

1. R. Dobbins, Aerosol Sci. and Techn 41, 485 (2007).

2. A. Ciajolo in: H. Bockhorn, A.D'Anna, A.F. Sarofim, H. Wang (eds), Combustion Generated Fine Carbonaceous Particles, KIT Scientific Publishing (2009), pp 333-344.

3. S.A. Ciatti, J.P. Hessler, K.O. Lee, A. Tentner, and J. Zhue, SAE International, 2005-010128 .

4. B.L. Wersborg, J.B. Howard, G.C. Williams, Proc. Combust. Inst. 14, 929 (1973).

5. B.L. Wersborg, A.C. Yeung, J.B. Howard, G.C., Proc. Combust. Inst. 14, 1439 (1975).

6. A. D’Alessio, A. D’Anna, A. D’Orsi, P. Minutolo, R. Barbella, A. Ciajolo, Proc. Combust. Inst. 24, 973 (1992).

7. P. Minutolo, G. Gambi, A. D’Alessio, A. D’Anna, Combust. Sci. and Tech. 101, 31 (1994).

8. R.L. VanderWal, Combust. Flame 112, 607 (1998).

9. R.A. Dobbins, in: F.L. Dryer, R.F. Sawyer (eds), Physical and Chemical Aspects of Combustion, pp. 107-133 (1998).

10. R.A. Dobbins, R.A. Fletcher, W. Lu, Combust. Flame 100, 301 (1995).

11. A.C. Barone, A. D’Alessio, A. D'Anna, Combust. Flame 132, 181 (2003).

12. L.A. Sgro, P. Minutolo, G. Basile, A. D’Alessio, Chemosphere 42, 671 (2001).

13. B Apicella, A. Ciajolo, I. Suelves, T.J. Morgan, A.A. Herod, R. Kandiyoty, Combust. Sci. and Techn. 174 (2002) 345-359.

14. B. Zhao, Z. Yang, J. Wang, M.V. Johnston, H. Wang, Aerosol Sci. Technol. 37, 173 (2003).

15. M.M. Maricq, Combust. Flame 137, 340 (2004).

16. B. Zhao, Z. Yang, Z. Li, M.V. Johnston, H. Wang, Proc. Combust. Inst. 30, 1441 (2005).

17. P. Minutolo, A. D’Anna, A. D’Alessio, Combust. Flame 152, 287 (2008).

18. H.-H. Grotheer, H. Pokorny, K.L. Barth, M. Aigner, Chemosphere 57, 1335 (2004).

19. A. D'Alessio, A. D'Anna, G. Gambi and P. Minutolo, J. Aerosol Sci. 29, 397 (1998).

20. P. Minutolo, A. D’Anna, A. D’Alessio, Combust. Flame 152, 287 (2008).

21. B.A. Mamyrin, Int. J. Mass Spectrom., 206, 261 (2001).

22. J. Ahrens, R. Kovacs, E.A. Shafranovskii, and K.H. Homann, Ber. Bunsenges. Phys. Chem. 98, 265 (1994).

23. J. Happold, H.-H. Grotheer, M. Aigner in: H. Bockhorn, A.D’Anna, A.F. Sarofim, H. Wang (eds), Combustion Generated Fine Carbonaceous Particles, KIT Scientific Publishing (2009), pp. 277-288.

24. A. Hospital, P. Roth, Proc. Combust. Inst. 23, 1573 (1990).

25. S. Fozin Foyet, Untersuchung des Ladungszustandes von Rußpartikeln in atmosphärischen Ethylen Luft Flammen, diploma thesis, KIT Karlsruhe, March 2010.

26. M. Gälli, S.A. Guazotti, K.A. Prather, Aerosol Sci. and Techn. 34, 381 (2001). 
27. V. Zimmermann, U. Näher, S. Frank, T.P. Martin, Large Clusters of Atoms and Molecules, Kluwer Academic, Dordrecht, The Netherlands, 1996, pp. 511-530.

28. J. Ahrens, A. Keller, R. Kocacs, K.-H. Homann, Ber. Bunsenges. Phys. Chem., 102, 1823 (1998).

29. H-H. Grotheer, K. Hoffmann, K. Wolf, K. Kanjarkar, C. Wahl, M. Aigner, Combust. Flame, 156, 791 (2009).

30. J. Happold, H.-H. Grotheer, M. Aigner, Rapid Comm. Mass Spectrom. 21, 1247 (2007).

31. Ph. Gerhardt, S. Löffler, K.-H. Homann, Proc. Combust. Inst. 22, 395 (1988).

32. A.T. Hartlieb, B. Atakan, K. Kohse-Höinghaus, Comb. Flame 121, 610 (2000).

33. K. Wolf, work under progress, to be published.

34. T. Gonzalez Baquet, H.-H. Grotheer, M. Aigner, Rapid Comm. Mass Spectrom. 21, 4060 (2007).

35. T. Gonzalez Baquet, Measurement of soot precursor particles under atmospheric and low pressure conditions by means of time-of-flight mass spectrometry. Dissertation thesis, University Stuttgart, 2009; VT-Forschungsbericht 2009-01, DLR

36. J. Happold, Geschichtete polyzyklische aromatische Kohlenwasserstoffe als Bausteine der Rußbildung. Dissertation thesis, University Stuttgart, 2008; Forschungsbericht 2008-05, DLR.

37. K.-H. Homann, Proc. Combust. Inst. 20, 857 (1984).

38. K.-H. Homann, E. Ströfer in: J. Lahaye, G. Prado (eds.), Soot in Combustion Systems and ist Toxic Properties, Plenum Press, New York, (1983), p. 217.

39. A. D'Anna, A. D'Alessio, P. Minatolo, in: H. Bockhorn (Ed.) Soot Formation in Combustion: Mechanisms and Models of Soot Formation, Springer Series in Chemical Physics 59, Springer-Verlag, Berlin, 1994, p. 83.

40. R.A. Dobbins, H. Subramaniasivam, in: H. Bockhorn (Ed.) Soot Formation in Combustion: Mechanisms and Models of Soot Formation, Springer Series in Chemical Physics 59, Springer-Verlag, Berlin, 1994, p. 290.

41. B. Zhao, Z. Yang, M.V. Johnston, H. Wang, A.S. Wexler, M. Balthasar, M. Kraft, Comb. Flame 133, 173 (2003).

42. H.X. Chen, R.A. Dobbins, Combust. Sci. and Tech. 159, 109 (2000).

43. R.A. Dobbins, R.A. Fletcher, H.-C. Chang, Combust. Flame 115, 285 (1998).

44. P. Minutolo, G. Gambi, A. D’Alessio, S. Carlucci, Atmos. Environ. 33, 2725 (1999).

45. L.A. Sgro, A. De Filippo, G. Lanzuolo, A. D’Alessio, Combust. Inst. 31, 631 (2007).

46. A. De Filippo, M. Commodo, P. Minutolo, L.A. Sgro, Proc. European Combust. Meeting, (2007) Crete, Greece.

47. A. D’Anna, A. Violi, Proc. Combust. Inst. 27, 425 (1998).

48. A. D'Anna, A. Violi, A. D'Alessio, Combust. Flame 121, 418 (2000).

49. A. Violi, A.F. Sarofim, T.N. Truong, Combust. Flame 126, 1506 (2001).

50. A. Violi, A. Kubota, T.N. Truong, W.J. Pitz, C.K. Westbrook,A.F. Sarofim, Proc. Combust. Inst. 29, 2343 (2002).

51. A. Violi, A.D'Anna, A. D’Alessio, A.F. Sarofim, Chemosphere 51, 1047 (2003).

52. A. Violi, Combust. Flame 139, 279 (2004).

53. A. D'Alessio, A. D'Anna, P. Minutolo, L.A. Sgro in: H. Bockhorn, A.D’Anna, A.F. Sarofim, H. Wang (eds), Combustion Generated Fine Carbonaceous Particles, KIT Scientific Publishing (2009), pp 205-230.

54. H.H. Grotheer, Combustion Colloquia 2009, $32^{\text {rd }}$ Meeting on Combustion, Italian Section of the Combustion Institute, Naples, April 26-28 (2009).

55. L.A. Sgro, A. Borghese, L. Speranza, A.C. Barone, P. Minutolo, A. Bruno, A. D’Anna, A. D'Alessio, Environ. Sci. Technol. 42, 859.

56. T. Ishiguro, Y. Takatori, K. Akihama, Combust, Flame 108, 231 (1997).

57. W. Merchan-Merchan, A.V. Saveliev, L.A. Kennedy, Comb. Sci. Techn. 175, 2217 
(2003).

58. H.A. Michelsen, F. Liu,B.F. Kock, H. Bladh, A. Boiarciuc, M. Charwath, T. Dreier, R. Hadef, M. Hofmann, J. Reimann, S. Will, P.-E. Bengtsson, H. Bockhorn, F. Foucher, K.-P. Geigle, C. Mounaim-Rousselle, C. Schulz, R. Stirn, r. Tribalet, R. Suntz, J. Appl. Phys. B 87, 503 (2007).

59. M.M. Maricq, Combust. and Flame 141, 406 (2005).

60. M.M. Maricq, Combust. and Flame 144, 730 (2006).

61. M.M. Maricq,J Aerosol. Sci. 37, 858 (2006).

62. M.M. Maricq,J Aerosol. Sci. 38, 141 (2007).

63. M.M. Maricq,J Aerosol. Sci. 39, 141 (2008).

64. H.F. Calcote, Combust. and Flame 42, 215 (1981).

65. A.B. Fialkov, Prog. Energy Combust. Sci. 23, 399 (1997).

66. J.H. Miller, J.D. Herdmann in: H. Bockhorn, A.D'Anna, A.F.

Sarofim, H. Wang (eds), Combustion Generated Fine Carbonaceous Particles, KIT Scientific Publishing (2009), pp 259-276. 


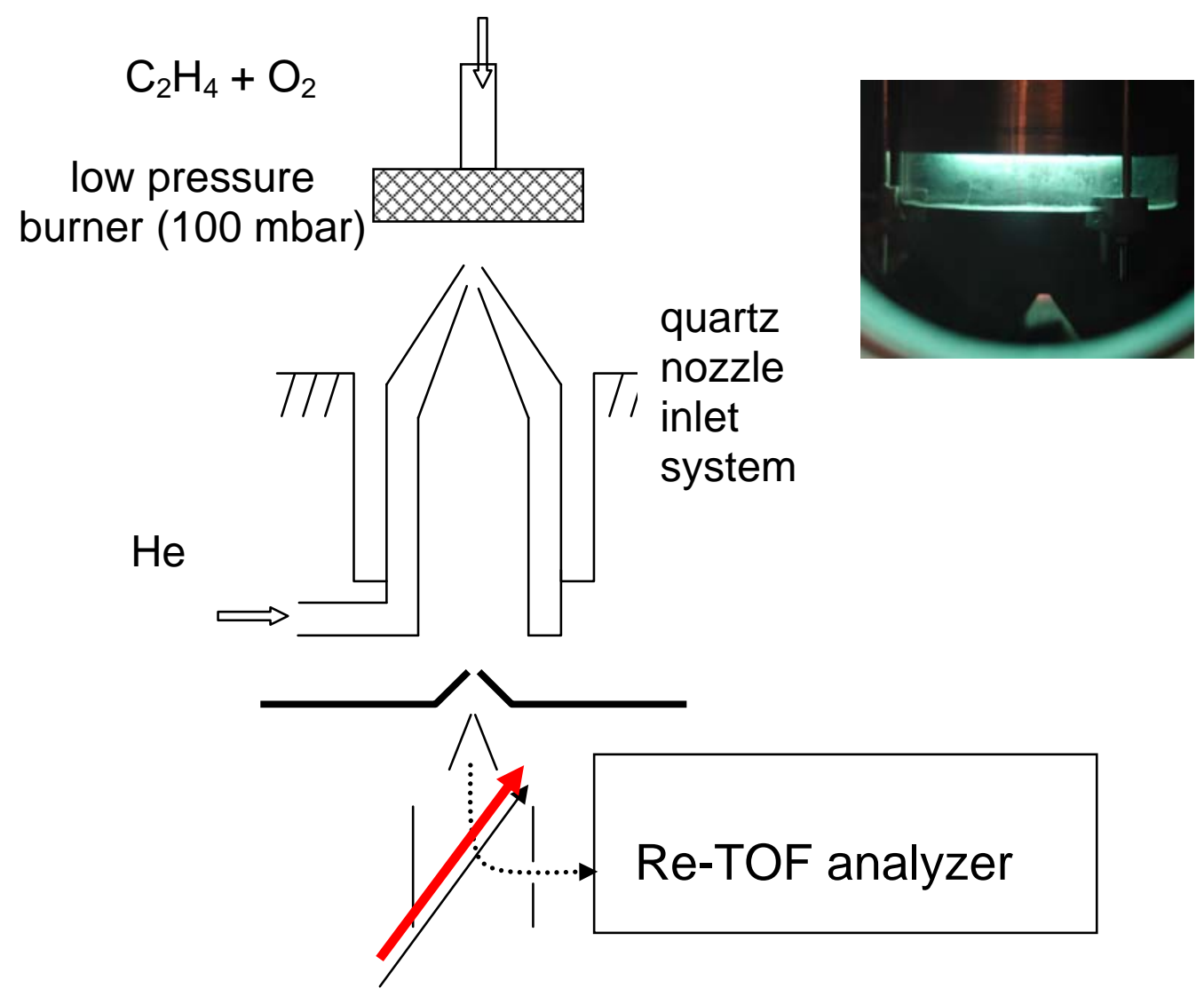

Fig. 1

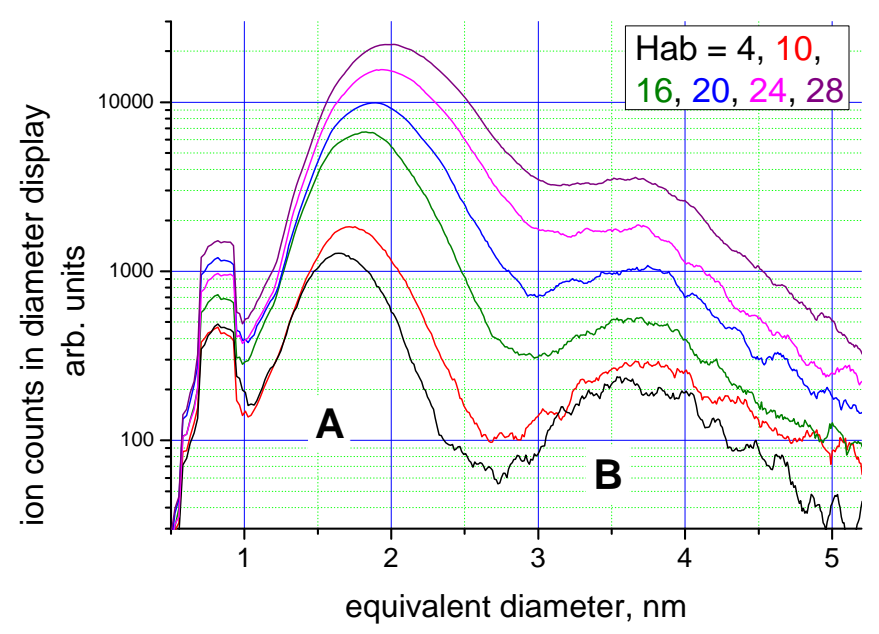

Fig. 2 


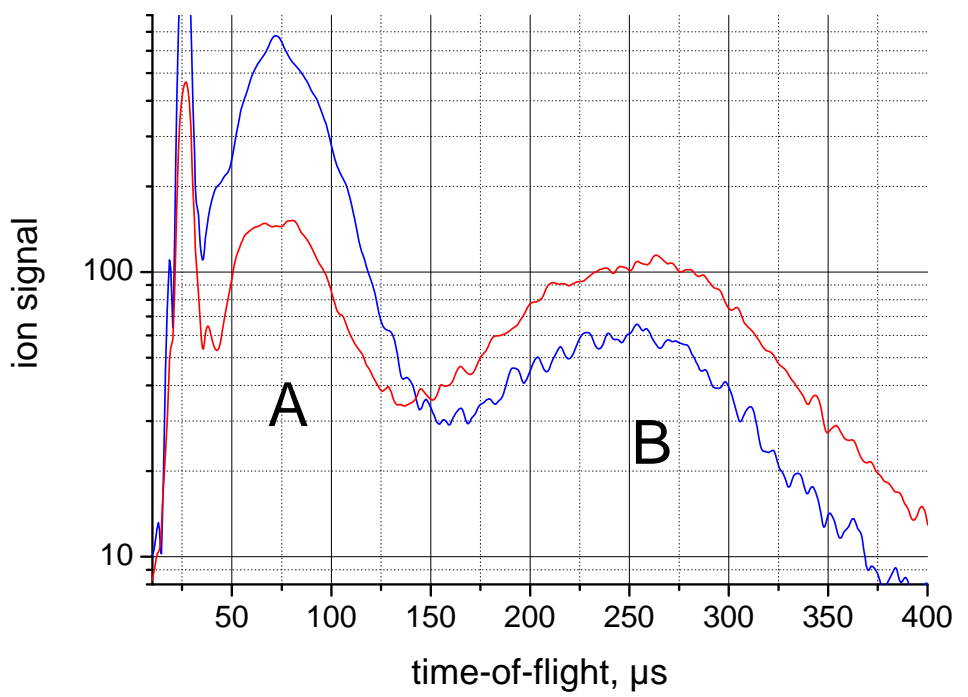

Fig. 3

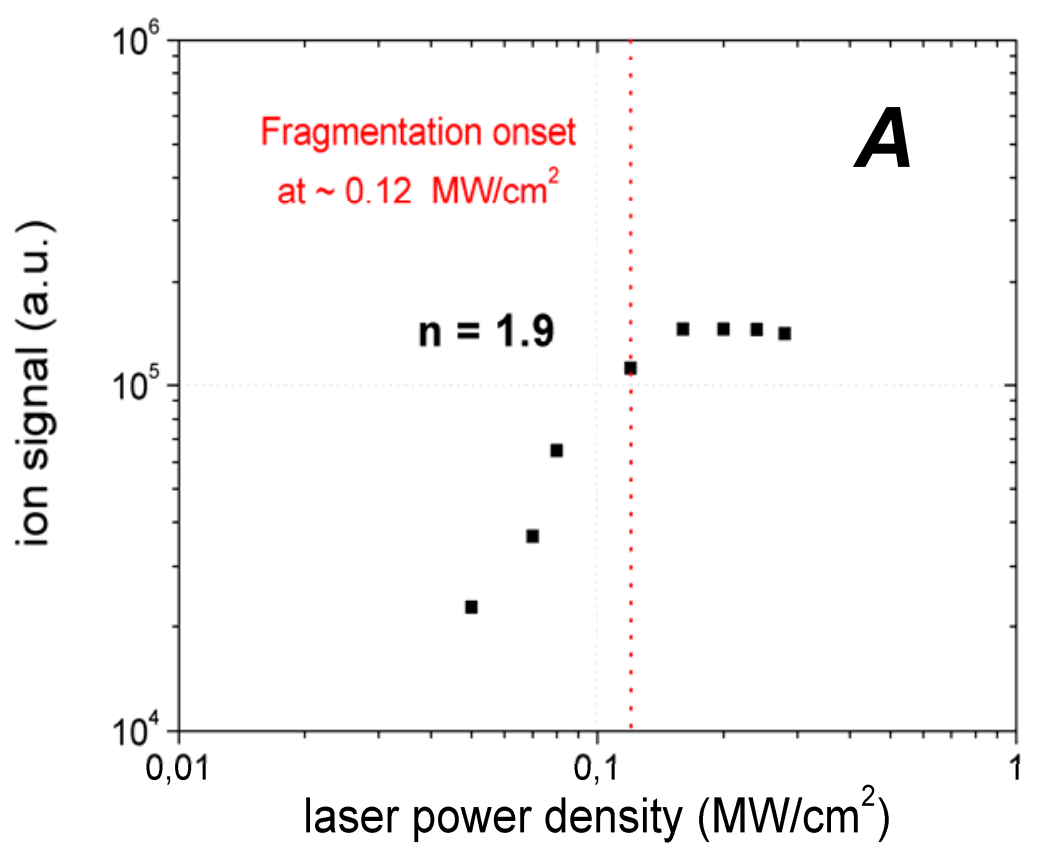

Fig. 4a 


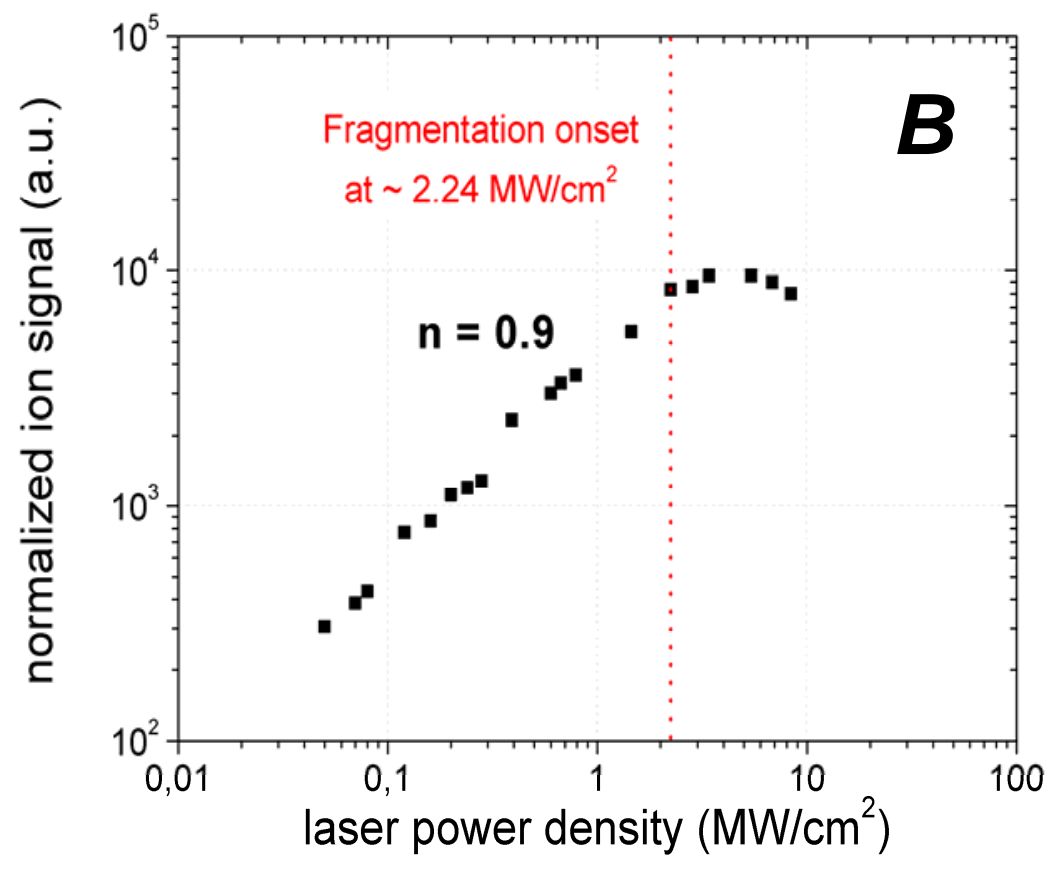

Fig. 4b

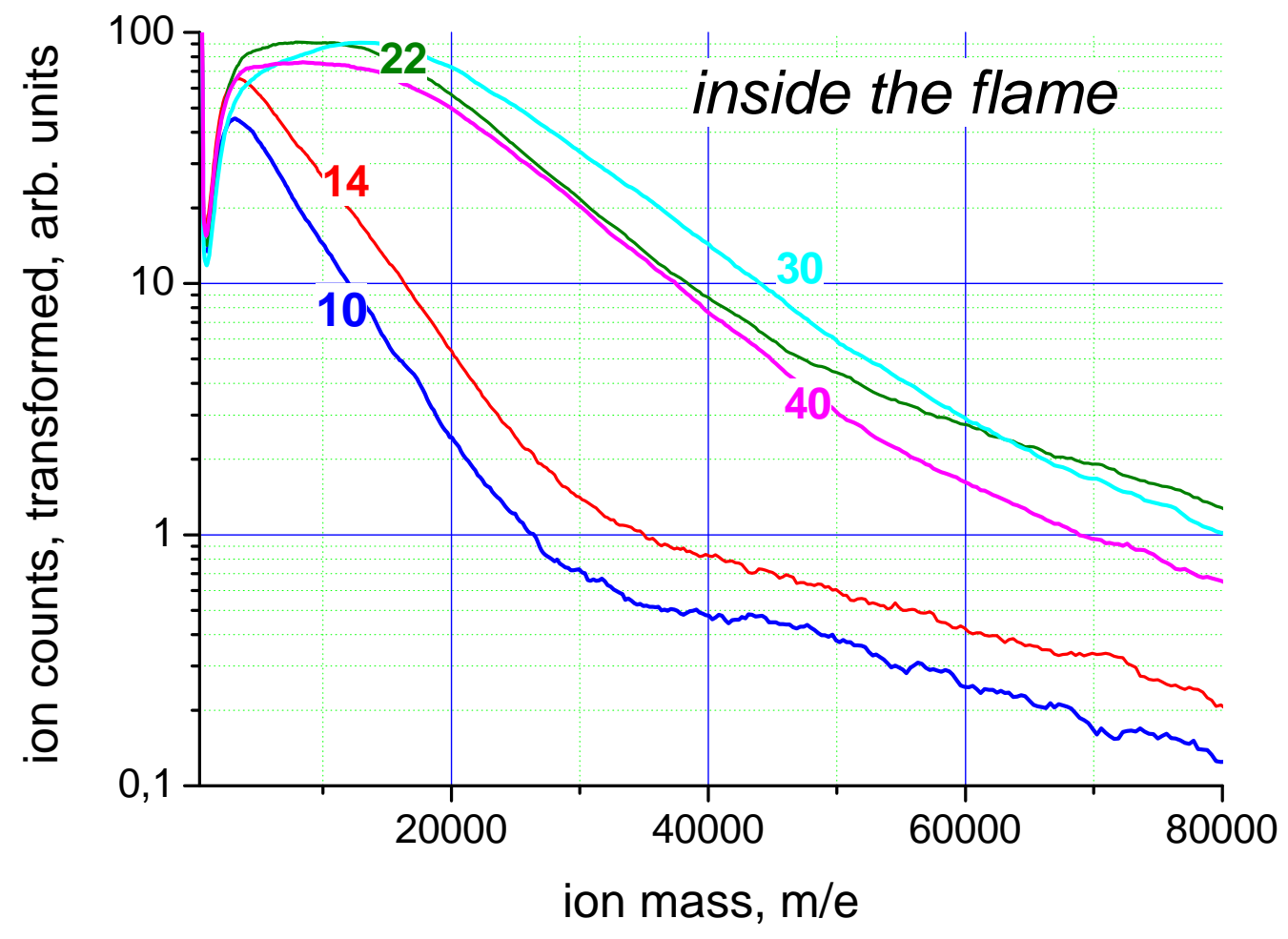

Fig. 5a 


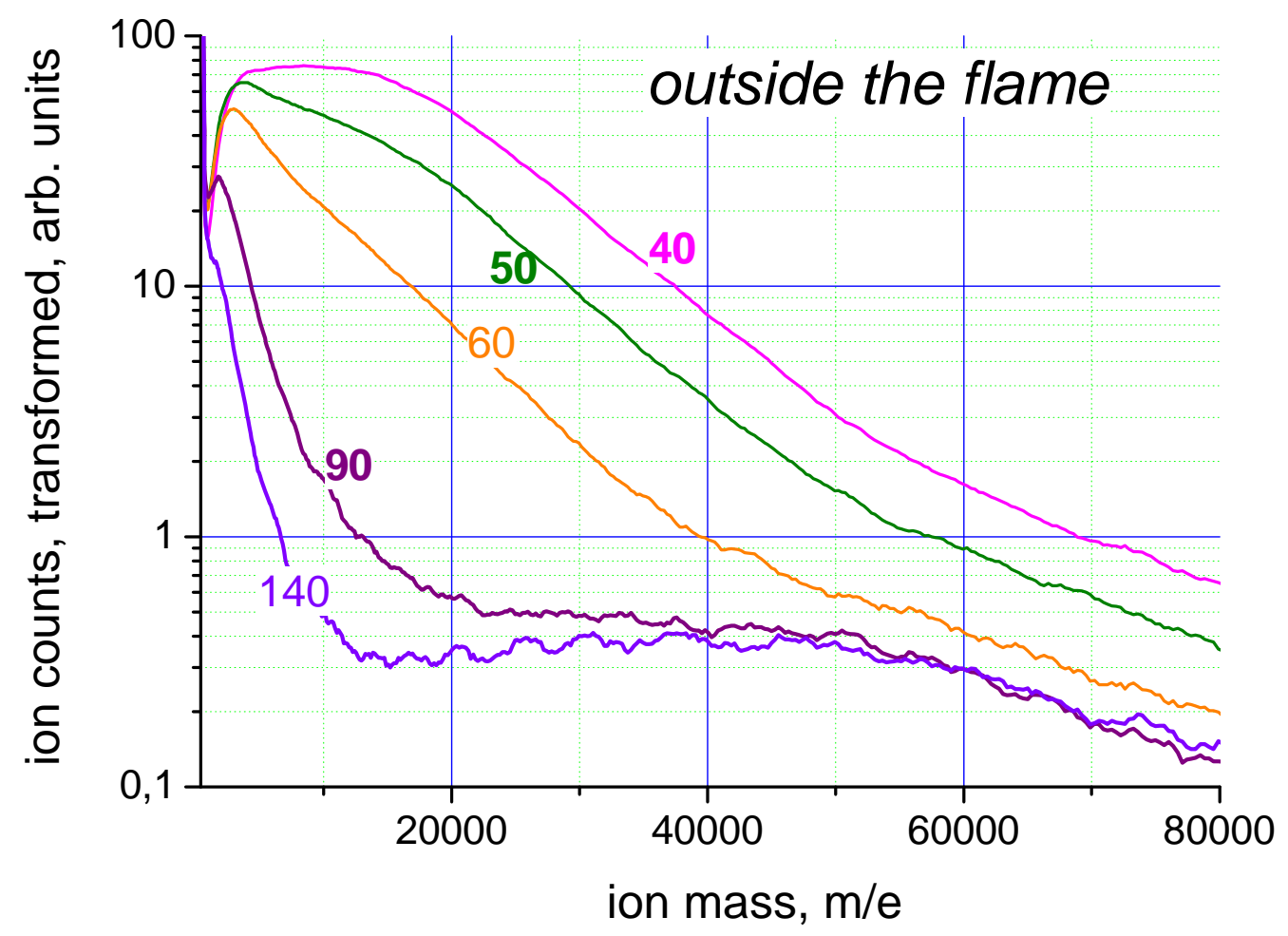

Fig. $5 b$

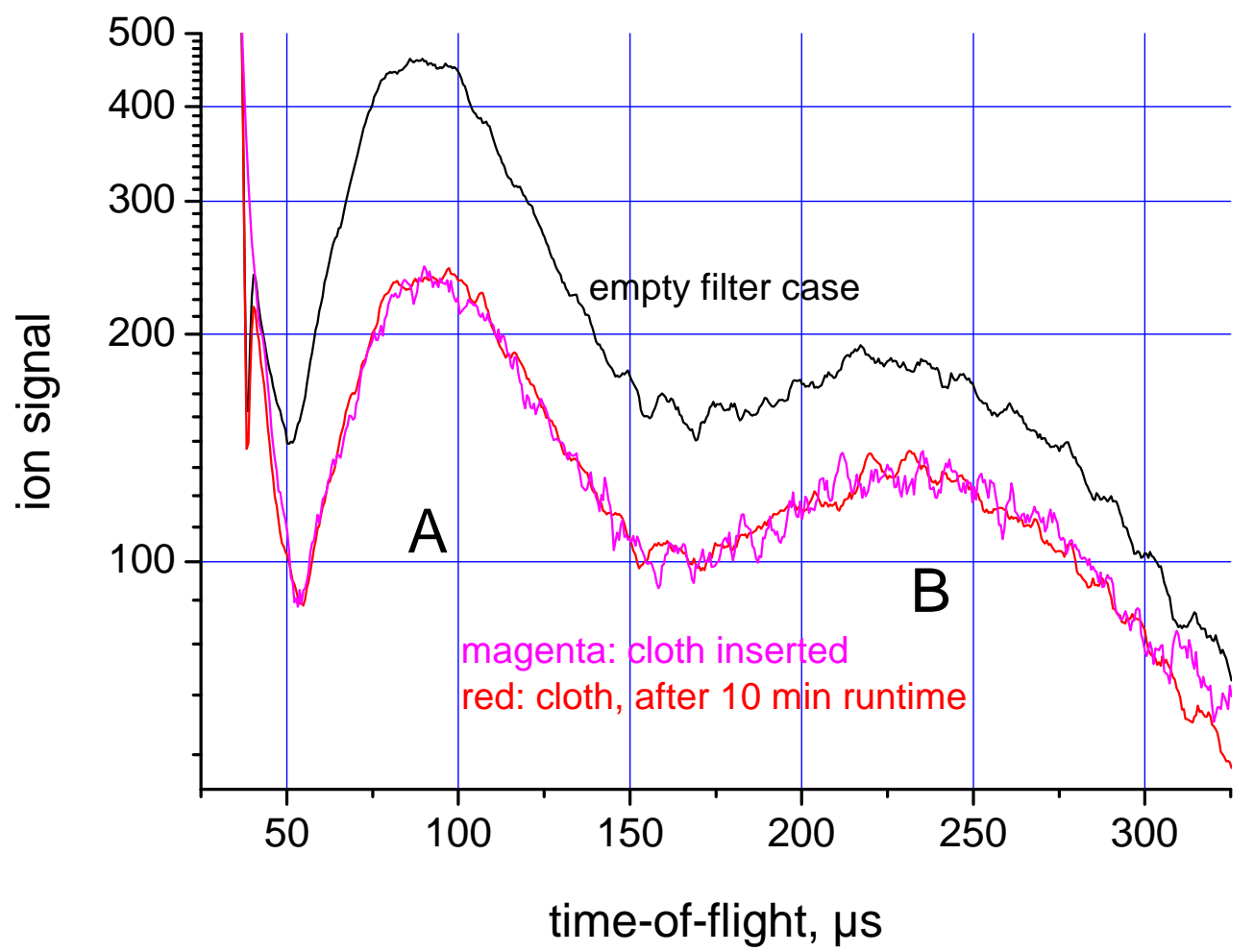

Fig. 6: 


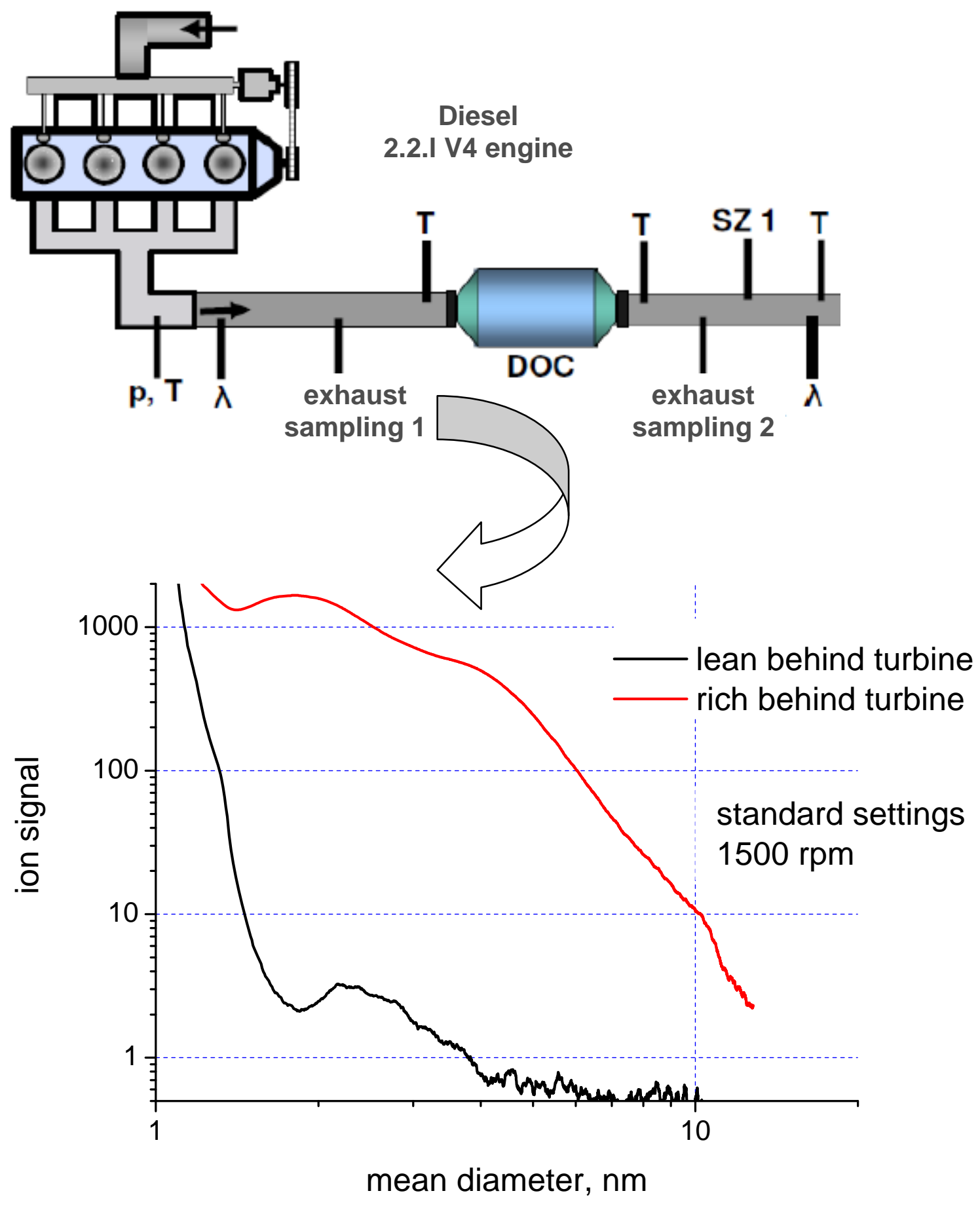

Fig. 7 


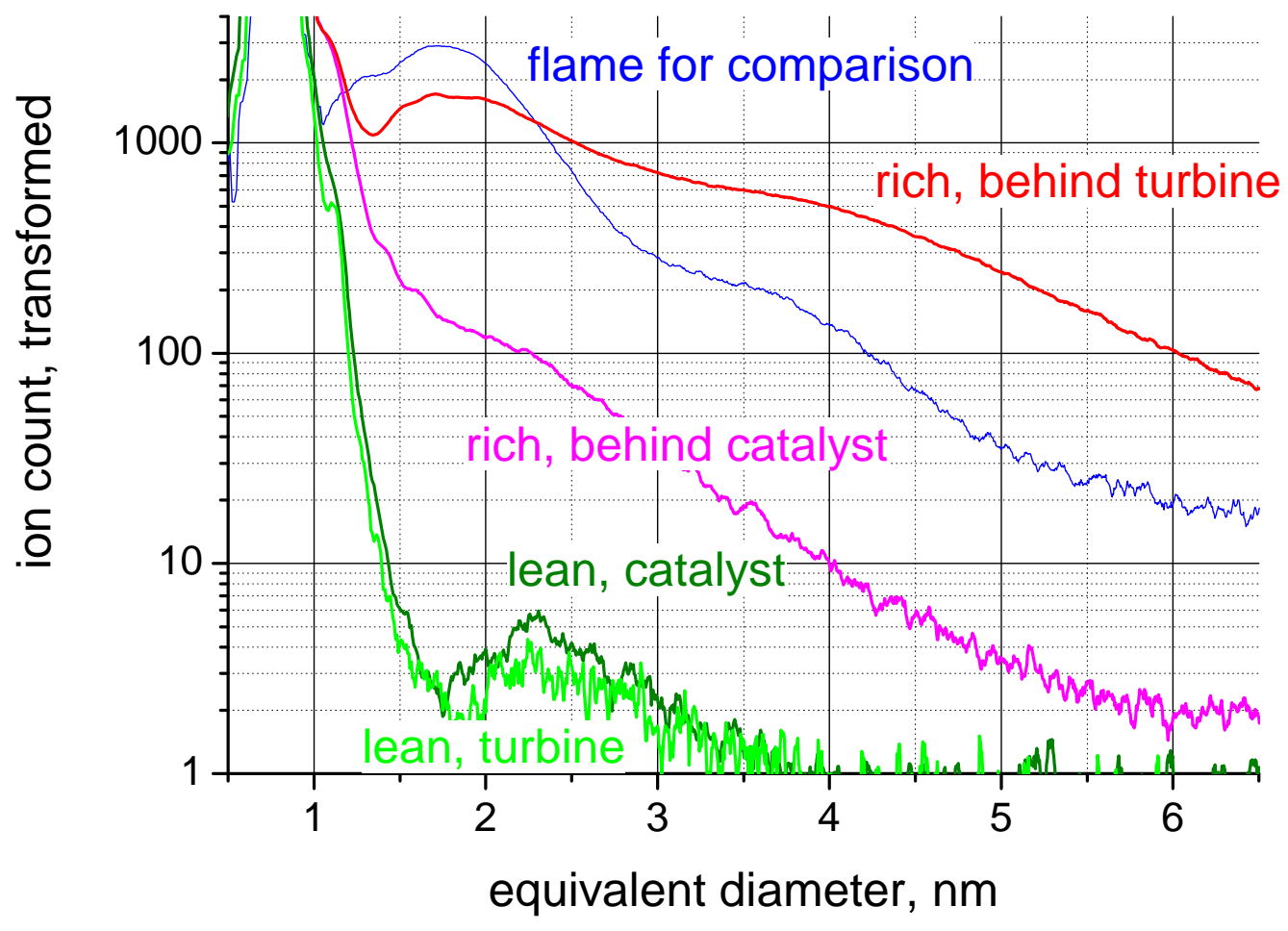

Fig. 8

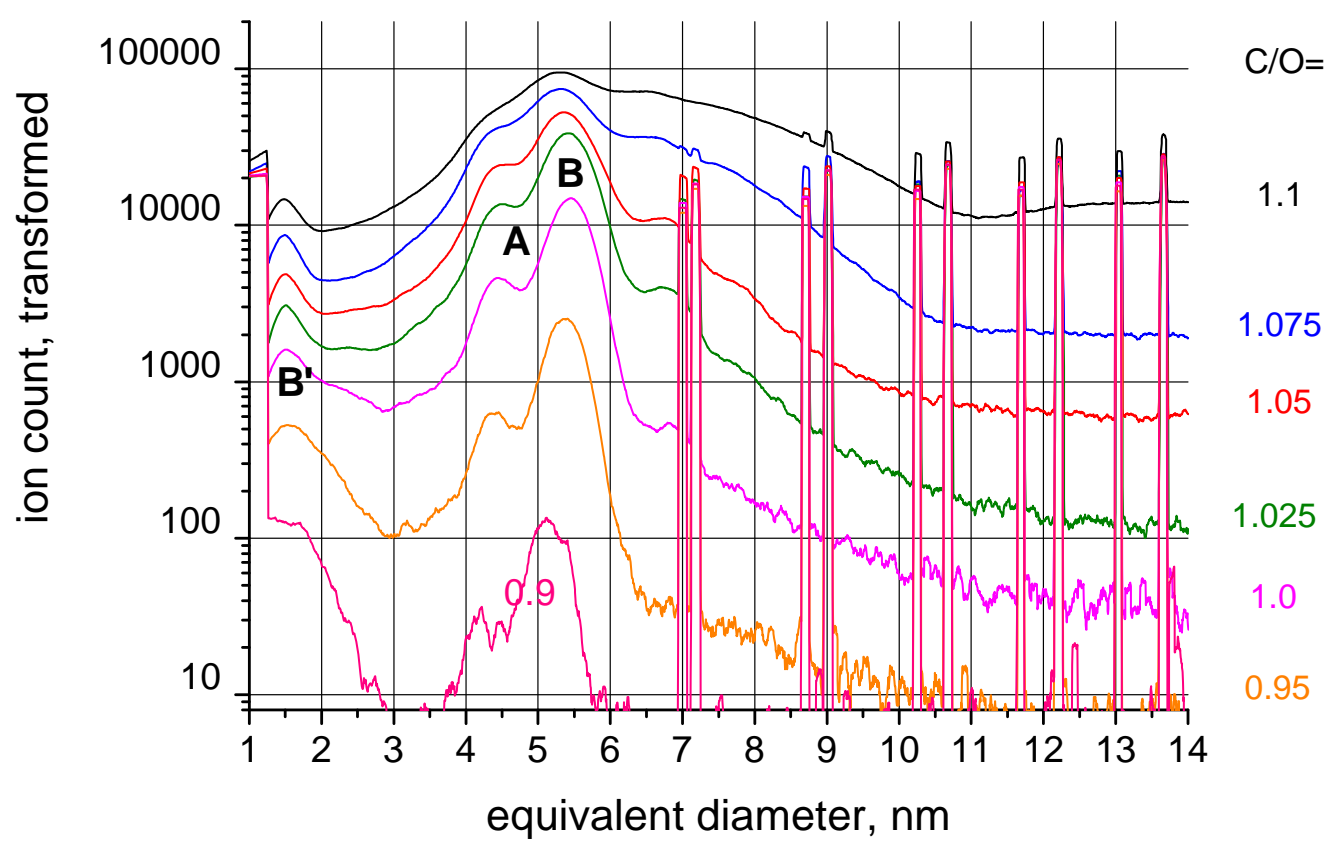

Fig. 9 


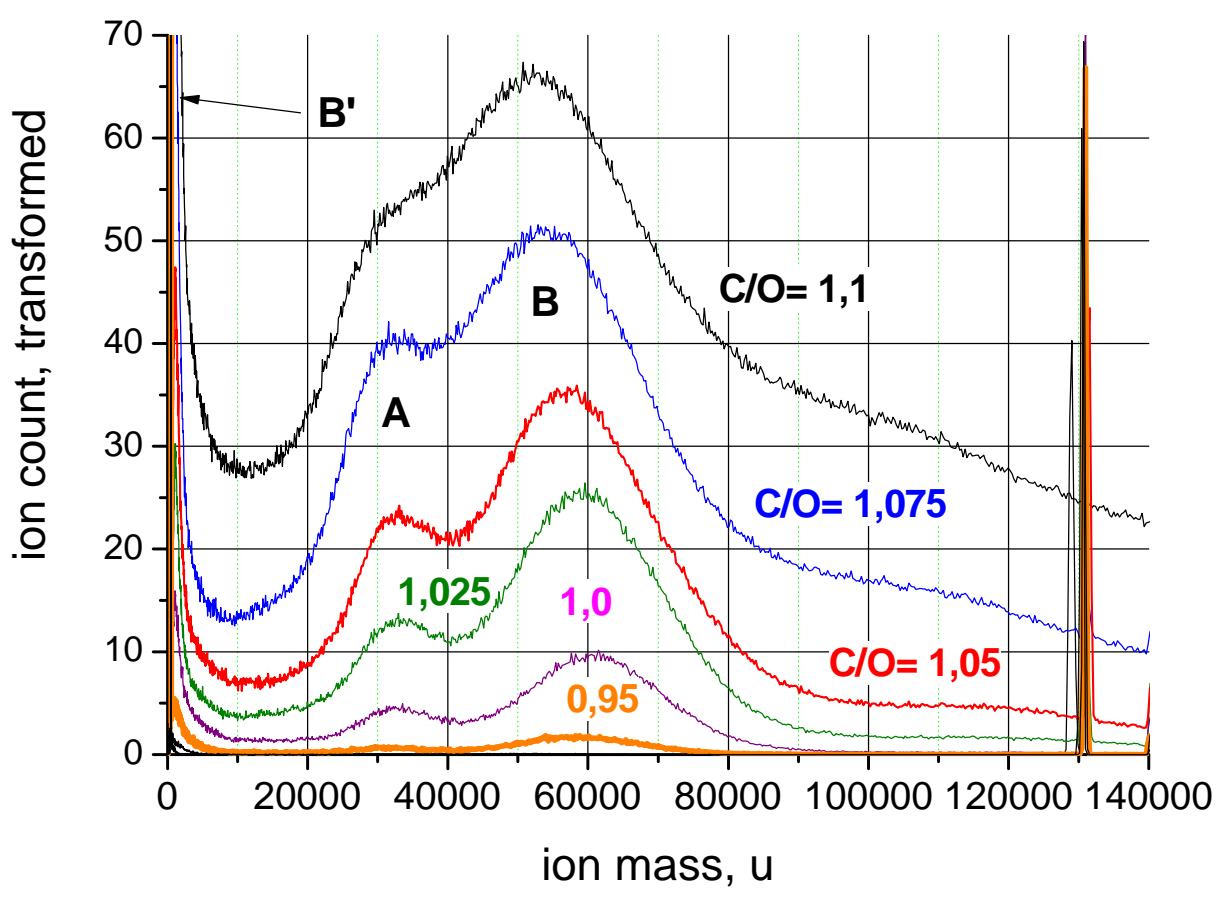

Fig. 9a

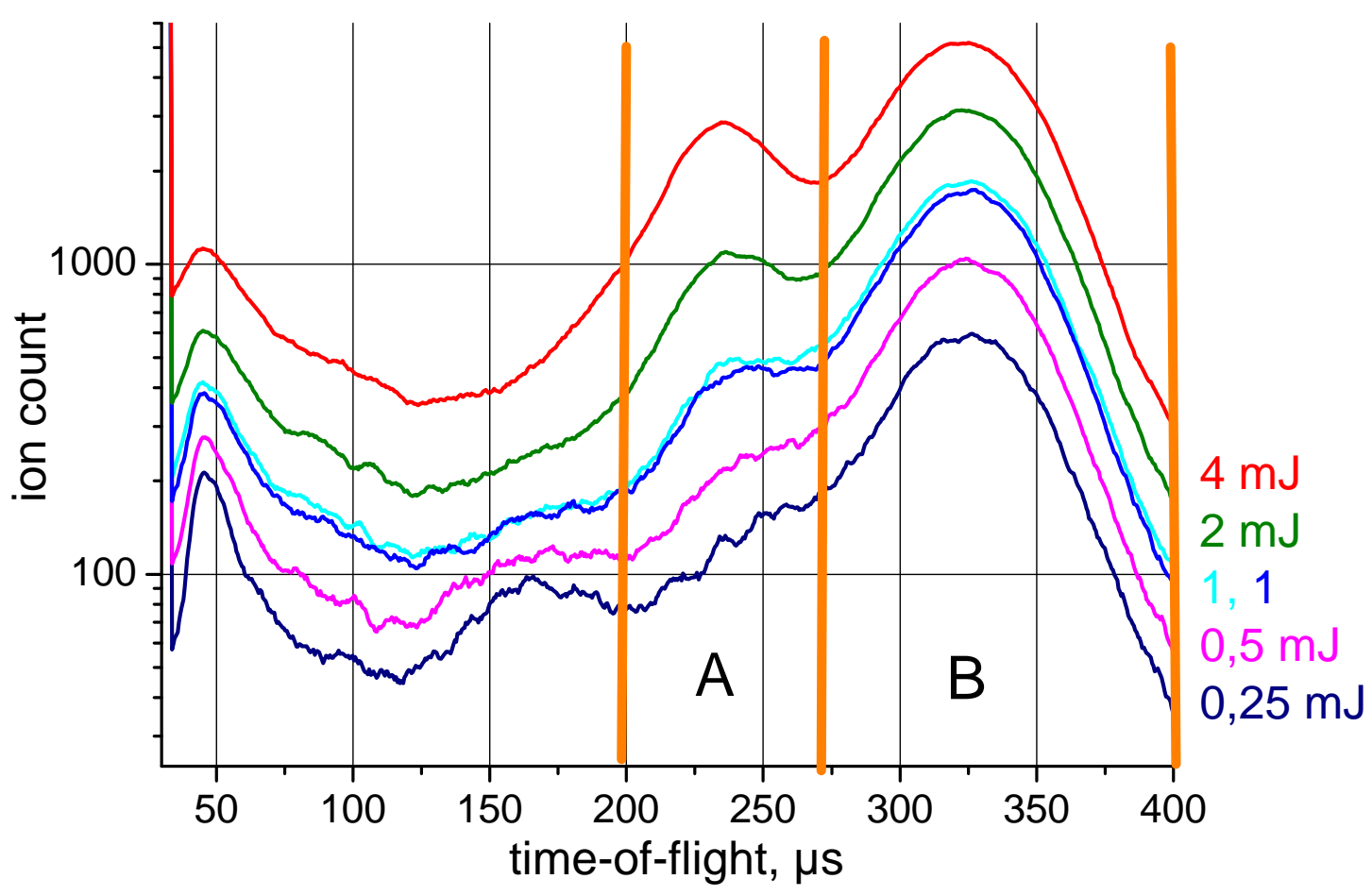

Fig. 10 


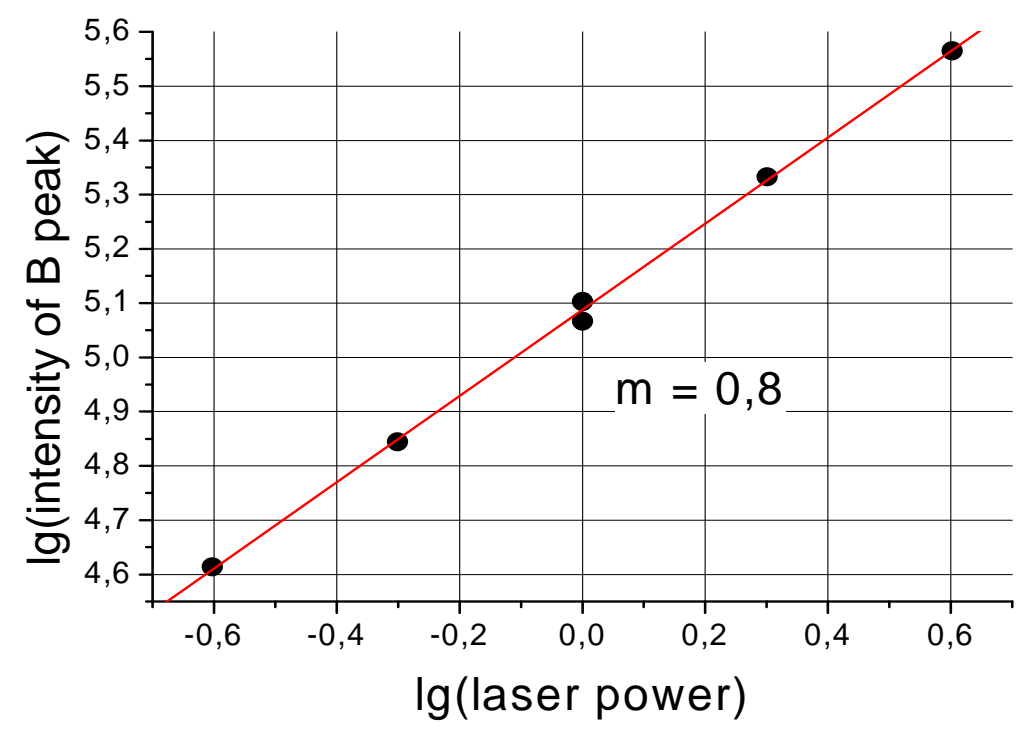

Fig. 10a

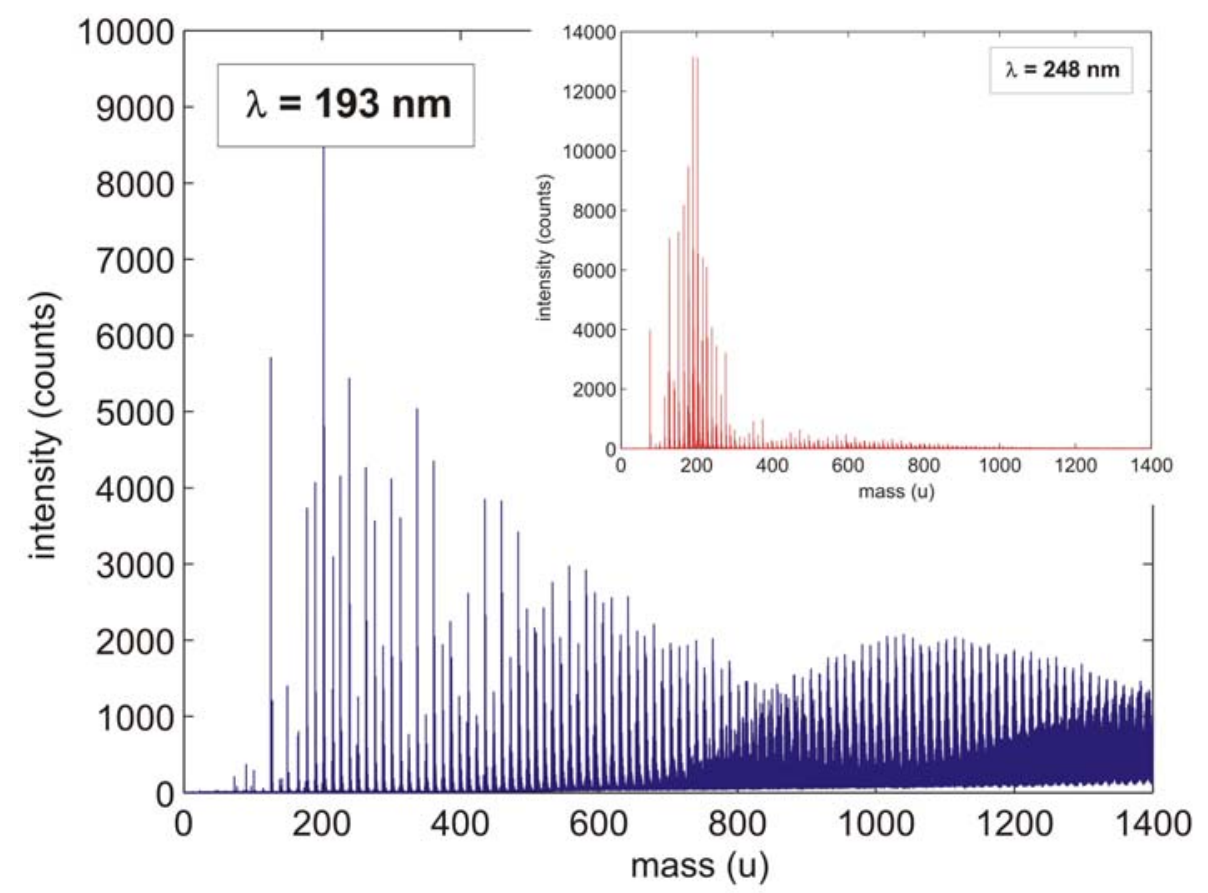

Fig. 11 


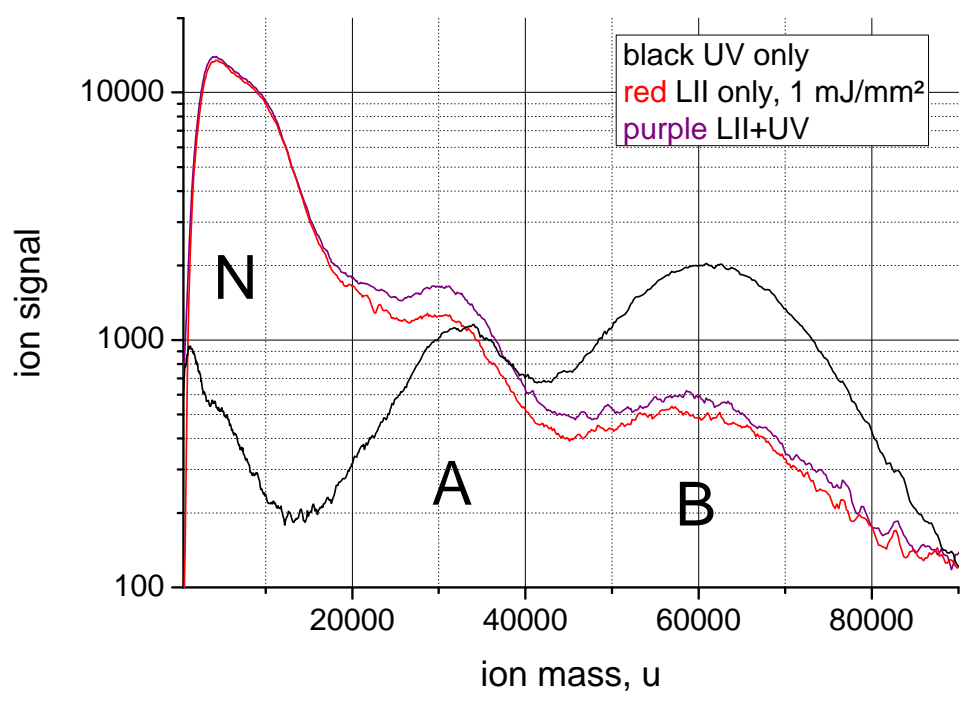

Fig. 12a

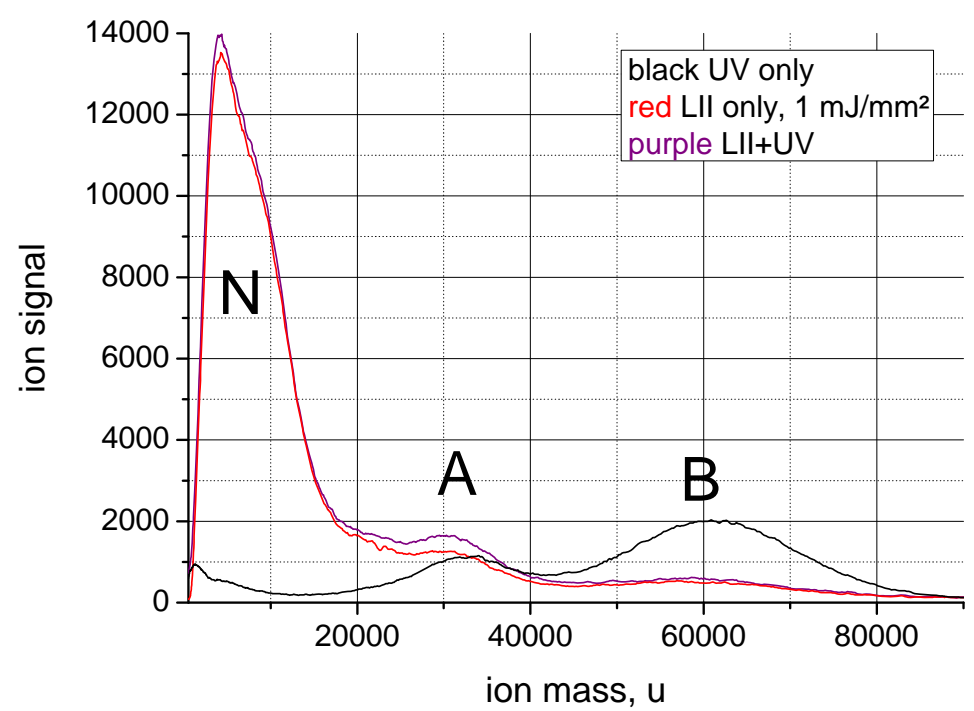

Fig. $12 b$ 


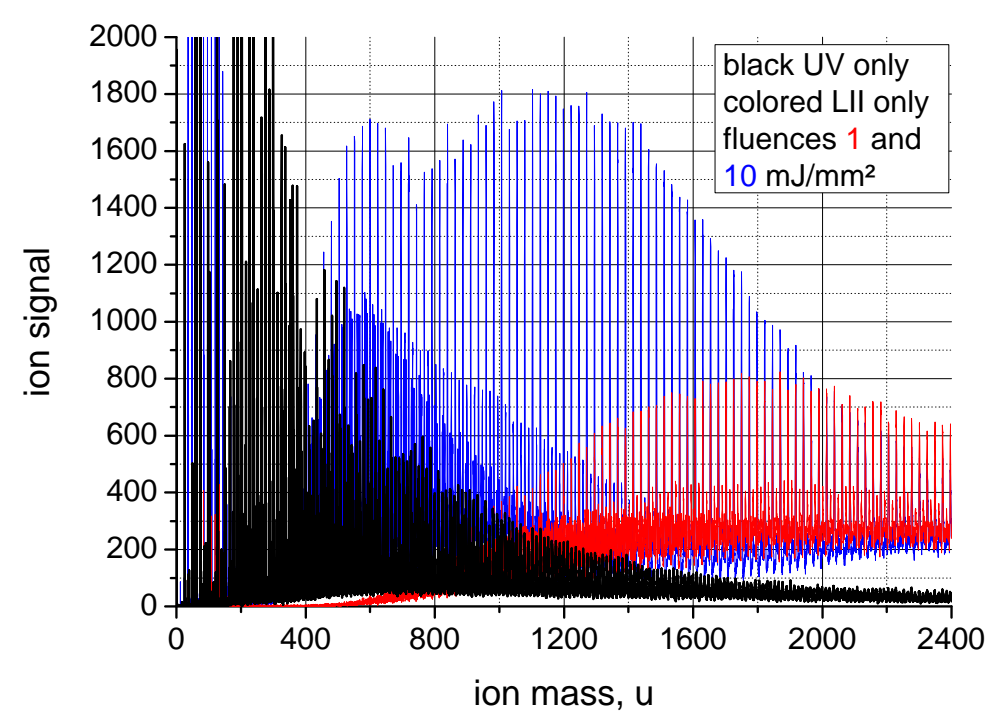

Fig. 13a

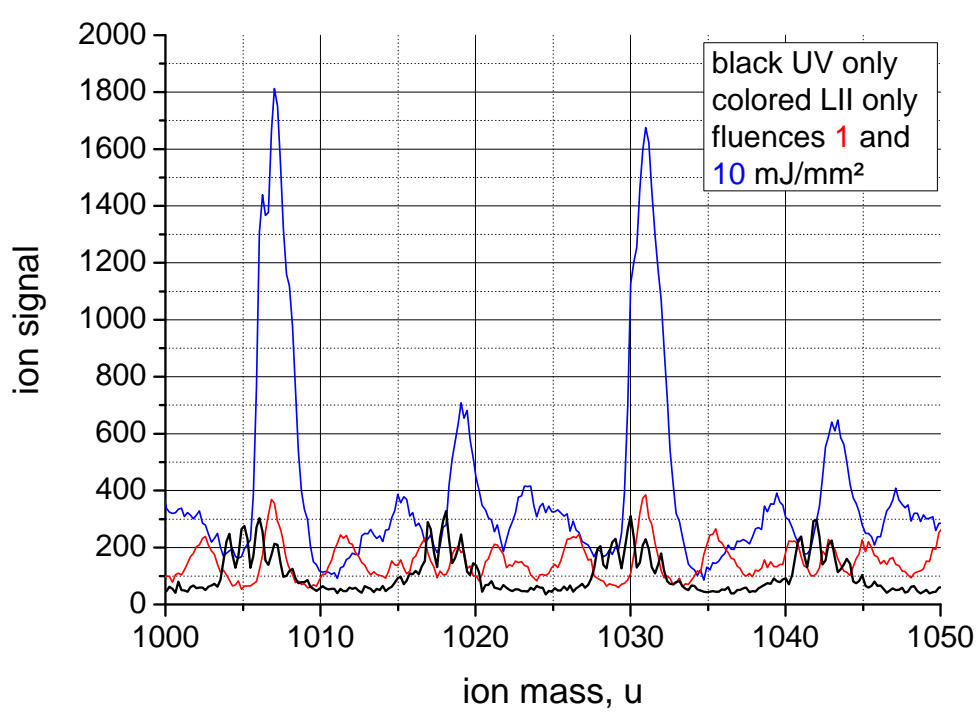

Fig. 13b 

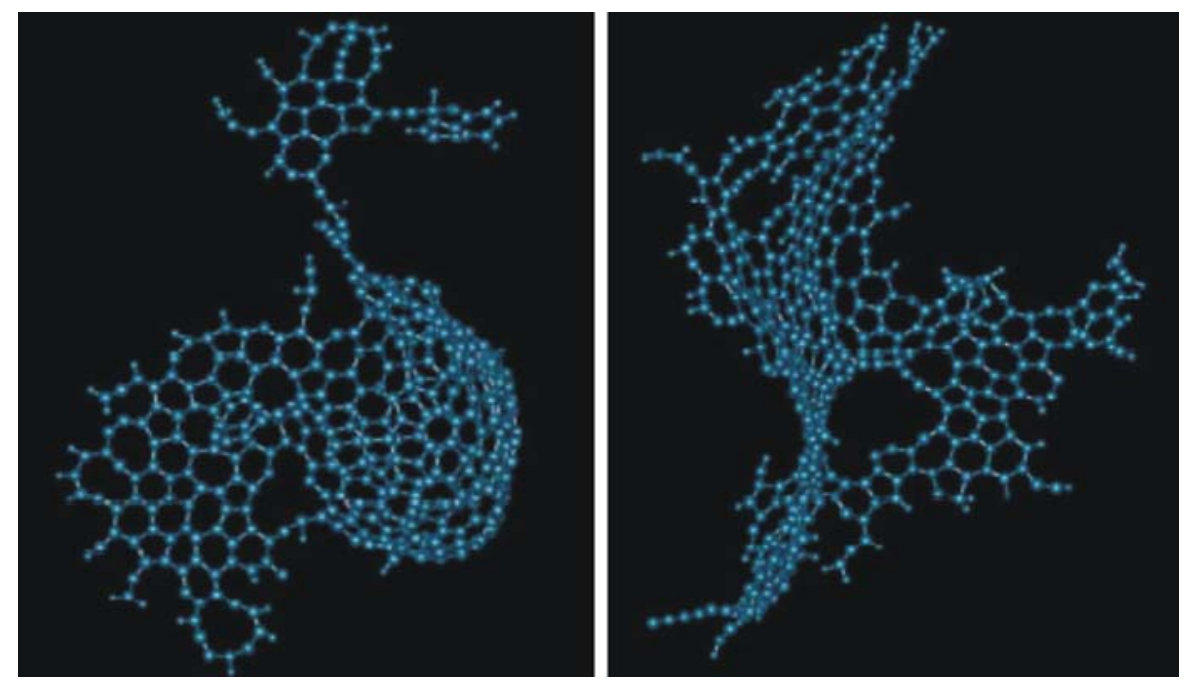

Fig. 14

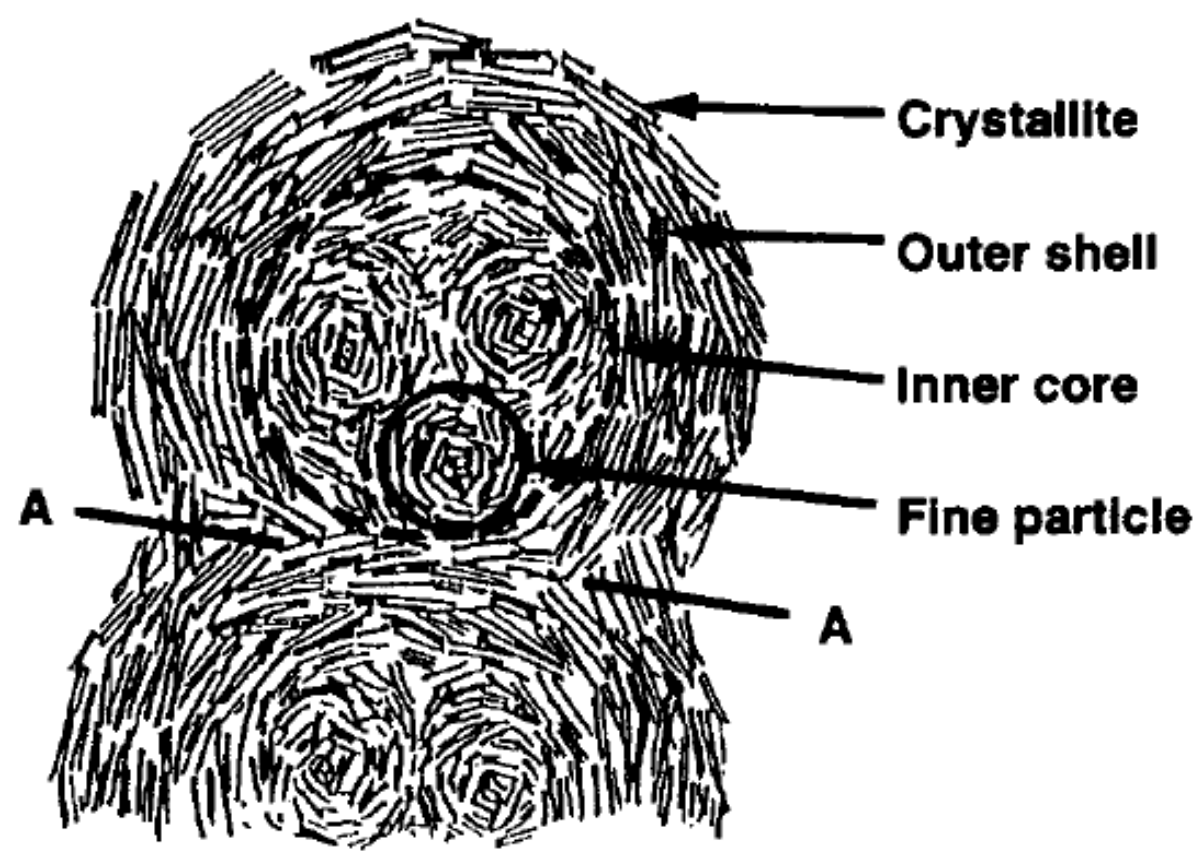

Fig. 15

Figure captions

Fig. 1: Setup for combined LII (IR) and UV experiments.

Fig. 2: PSDFs of nascent nanoparticles as a function of height above burner (HaB) $\mathrm{C}_{2} \mathrm{H}_{4}$-air flame, $\mathrm{C} / \mathrm{O}=0.62, \mathrm{v}_{\mathrm{u}}=7.5 \mathrm{~cm} / \mathrm{s}$. 
Fig. 3: Nanoparticle time-of-flight spectra behind an $\mathrm{C}_{2} \mathrm{H}_{4}$ air flame, blue, $\mathrm{v}_{\mathrm{u}}=5.7 \mathrm{~cm} / \mathrm{s}$ and behind an $\mathrm{C}_{2} \mathrm{H}_{4} / \mathrm{O}_{2}$ flame, red, $\mathrm{v}_{\mathrm{u}}=4.5 \mathrm{~cm} / \mathrm{s}, \mathrm{C} / \mathrm{O}=0.62$ in both cases.

Fig. 4a: Ion signals as a function of laser power density (= fluence) for A mode.

Fig. $4 \mathrm{~b}$ : the same for B mode.

Fig. 5a: Nanoparticle profiles (mass distributions) as a function of $\mathrm{Hab}$, inside of an $\mathrm{C}_{2} \mathrm{H}_{4}$ air flame, $\mathrm{v}_{\mathrm{u}}=5.2 \mathrm{~cm} / \mathrm{s}, \mathrm{C} / \mathrm{O}=0.7$.

Fig. 5b: Profiles as in Fig. 5a, yet outside the flame.

Fig. 6: Effect of a cotton cloth filter positioned $25 \mathrm{~cm}$ downstream of the sampling nozzle. Upper trace: empty filter case.

Lower traces: Magenta. Cloth inserted, red: after 10 minutes run time.

Fig. 7: Nanoparticles behind a commercial Diesel engine (see text).

Upper trace $\Phi=1$, lower trace $\Phi=0.5$.

Fig. 8: Effect of oxidation catalytist on nanoparticles. For nanoparticles generated under rich conditions $94 \%$ destruction through catalyst. No effect for nanoparticles generated under lean conditions. Blue trace: flame profile for calibration.

Fig. 9: Nanoparticle PSDFs behind a low pressure $\mathrm{C}_{2} \mathrm{H}_{4} / \mathrm{O}_{2}$ flame $(\mathrm{p}=126 \mathrm{mbar}$, $\left.\mathrm{v}_{\mathrm{u}}=10.6 \mathrm{~cm} / \mathrm{s}, \mathrm{Hab}=40 \mathrm{~mm}\right)$.

Fig. 9a: Same data as in Fig. 9, yet in mass display.

Fig. 10: Dependence of PSDFs shown in Fig. 9 on laser fluence (pulse energy of $1 \mathrm{~mJ} /$ pulse corresponds to fluence of $0.15 \mathrm{MW} / \mathrm{cm}^{2}$ ).

Fig. 11: Exhaust gas spectrum in high resolution of a low pressure $\mathrm{C}_{2} \mathrm{H}_{4} / \mathrm{O}_{2}$ flame with wavelike structure extending in the mass region beyond $1000 \mathrm{u}$. Photoionization using 193 nm. Inset: $248 \mathrm{~nm}$ photoionization.

Fig. 12a: Influence on IR irradiation on nanoparticle profiles (see text), log display.

Fig. 12b: Data of Fig. 12a, yet lin display.

Fig. 13a: Undisturbed peak distribution in high resolution of flame exhaust gas (black) and peaks of particles newly formed upon IR irradiation ( red: fluence $1 \mathrm{~mJ} / \mathrm{mm}^{2}$, blue: fluence $1 \mathrm{~mJ} / \mathrm{mm}^{2}$ ).

Fig. 13b: Small portion of Fig. 13a in expanded view. Note: Satisfying resolution for "UV only" trace. Poor resolution of IR generated traces obtained with the same setting of mass spectrometer.

Fig. 14: Calculated structure of an A-particle formed in a benzene (left) and an acetylene flame. Taken from Violi ${ }^{52}$.

Fig. 15: Schematic model of microstructure of the Diesel soot particle. Taken from Ishiguro et al. ${ }^{56}$. 